FINANCIAL INTERMEDIATION AND

THE GREAT DEPRESSION:

A MULTIPLE EQUILIBRIUM

INTERPRETATION

\author{
Russell Cooper \\ João Ejarque
}

Working Paper No. 5130

\author{
NATIONAL BUREAU OF ECONOMIC RESEARCH \\ 1050 Massachusetts Avenue \\ Cambridge, MA 02138 \\ May 1995
}

We are grateful to Paul Beaudry, Ben Bernanke, Simon Gilchrist, John Haltiwanger, Robert King, Charles Plosser, Sergio Rebelo and Steve Williamson for discussions on this topic, to Alok Johri for help with the data and to the National Science Foundation and JNICT for financial support. Seminar participants at the November 1994 Carnegie-Rochester Conference, the Innocenzo Gasparina Institute for Economic Research, the University of Bologna, the Universite du QuebecMontreal and the Texas Monetary Conference provided numerous questions that helped to improve this paper. This paper is part of NBER's research program in Economic Fluctuations. Any opinions expressed are those of the authors and not those of the National Bureau of Economic Research.

(C) 1995 by Russell Cooper and João Ejarque. All rights reserved. Short sections of text, not to exceed two paragraphs, may be quoted without explicit permission provided that full credit, including $\odot$ notice, is given to the source. 
NBER Working Paper \#5130

May 1995

\title{
FINANCIAL INTERMEDIATION AND \\ THE GREAT DEPRESSION: \\ A MULTIPLE EQUILIBRIUM \\ INTERPRETATION
}

\begin{abstract}
This paper explores the behavior of the U.S. economy during the interwar period from the perspective of a model in which the existence of non-convexities in the intermediation process gives rise to a multiplicity of equilibria. The resulting indeterminancy is resolved through a sunspot process which leads to endogenous fluctuations in aggregate economic activity. From this perspective, the Depression period is represented as a regime shift associated with a financial crisis. Our model economy has properties which are broadly consistent with observations over the interwar period. Contrary to observation, the model predicts a negative correlation of consumption and investment as well as a highly volatile capital stock. Our model of financial crisis reproduces many aspects of the Great Depression though the model predicts a much sharper fall in investment than is observed in the data. Modifications to our model (adding durable goods and a capacity utilization choice) do not overcome these deficiencies.
\end{abstract}

Russell Cooper

Department of Economics

270 BSR

Boston University

Boston, MA 02215

and NBER
João Ejarque

Department of Economics

270 BSR

Boston University

Boston, MA 02215 


\section{Introduction}

This paper explores the behavior of the U.S. economy during the interwar years, with particular emphasis on the Great Depression period. We do so from the perspective of models in which the presence of a strategic complementarity leads to multiple steady state equilibria and indeterminacy. Informal discussion of models with multiple equilibria often point to the Great Depression as an example of a low activity level equilibrium. In this study we take this view seriously using a particular model of multiple equilibria built upon financial fragility.

In particular, we focus on the breakdown of the intermediation process which, as argued by Bernanke [1983] and others, was key to understanding this period. As is discussed by Friedman and Schwartz [1963], the Great Depression was characterized by numerous bank failures, episodes of bank runs, a rapid fall in both the deposit to currency ratio and the deposit to reserve ratio as well as a decrease in the ratio of loans to securities in bank portfolios. ${ }^{1}$ Bernanke argues that this collapse of the intermediation process was critical for the length and depth of the Depression.

To study these issues, we specify a model in which confidence in the intermediation process plays a central role in the decision making of optimizing agents. Due to complementarities in the intermediation process, the economy can have either a relatively active (thick) or inactive (thin) financial system. We use a sunspot approach to resolve this indeterminacy and explore the implications of such an equilibrium for key aggregate variables. Thus our ultimate goal is to characterize the macroeconomic implications of a

\footnotetext{
1 Friedman and Schwarz [1963] provides a detuiled diecuacion of the behavior of both real and financial variables over this period.
} 
model in which fluctuations are driven by periods of optimism and pessimism associated with the returns from financial intermediation. In doing so, we are able to evaluate the predictions of the model for non-financial variables.

Our emphasis on regime shifts due to multiple equilibria and the role of intermediation shocks is partly motivated by Figure 1. This figure displays investment along with the unexplained component of investment from the linearized real business cycle model of King, Plosser and Rebelo [1988] in which the capital stock and the Solow residual serve as state variables. ${ }^{2}$ The linear relationship of this real business cycle model appears not to fit very well over this period. In particular, the 1930-35 investment experience in the U.S. economy is largely unexplained by variations in the Solow residual and the capital stock. Note too that there appears to be a non-linear structure to the residuals. This issue of a regime shift, suggested by these figures and Coe [1995], is taken up in considerable detail later in the paper.

To better approximate the behavior of investment and other aggregate variables, our model adds two features to the standard model. The first is the prospect of a regime shift arising in an economy with multiple equilibria. This allows us to capture the non-linearities in the data. The second is the addition of financial crises, motivated by Bernanke [1983]. The question is whether the addition of financial instability through the multiple equilibrium approach is able to explain the movements in investment, output and consumption during this period.

\footnotetext{
2 The data are in per capita terms and have been converted to per cent doviations around a linear trend. The Solow residual was calculated uking a Labor factor share of .65 which is appropriate for this time period. From the King. Plower and Rebelo calibration of the "LongPloser Model with realistic depreciation", the coefficient on capital wes .629 and that on the Solow residual was 4.73.
} 
Our model displays many of the properties of other models in which strategic complementarities play a central role. ${ }^{3}$ As is common in models with strategic complementarities, the steady states can generally be Pareto-ranked leading to the possibility of coordination failure. In contrast to single agent models, while there are $\$ 100$ bills lying on the sidewalk in these economies, it takes the coordinated efforts of multiple agents to pick them up. Further, our model economy generates persistent fluctuations without requiring the presence of serially correlated shocks to exogenous fundamentals. To us, these features are consistent with interpretations of the Great Depression: the breakdown of the intermediation process was a coordination failure that persisted until actions were taken by the Government to bolster confidence. The fact that similar episodes have not been observed since the Depression attests to the powerful role played by deposit insurance introduced in $1934 .{ }^{4}$

In terms of quantitative implications, our model reproduces many features of aggregate fluctuations including consumption smoothing and large movements in investment relative to output. However, the breakdown of the intermediation process creates a negative correlation between consumption and investment and a highly volatile capital stock, in contrast to observation during both the interwar and post WWII periods. Modifications to the model, through the additions of consumer durables and a capacity utilization choice, do not alter these implications. The model does capture many aspects of the Great Depression though relative to observation the predicted fall in investment is too big and hours do not fall

\footnotetext{
S See Cooper and John [1988] for a discuncion of mecroeconomic modele with trutegic complementurities and muhiple equilibria. - Gondon [1986] discumes the important mabilization role of deponit insurance in hit introductory commente on the changing aructure of business cycles.
} 
enough.

The paper also makes a number of methodological contributions. First, it continues research on the quantitative implications of models in which sunspots play a prominent role as a source of fluctuations. ${ }^{5}$ Second, the paper provides a model of regime changes which is complementary to some recent work, discussed further below, on non-linear time series.

\section{Model}

We consider an economy which is an extension of the stochastic growth model used, for example, by King, Plosser and Rebelo [1988] to study aggregate fluctuations. In particular, households in our economy work, obtain consumptions goods and accumulate capital. The unique feature of our approach is to consider a stochastic capital accumulation process which reflects the strategic interaction of agents. In our economy, the strategic interaction can generate a multiplicity of equilibria and thus an endogenous source of fluctuations that impacts accumulation directly. ${ }^{6}$ We provide two ways of thinking about these interactions across agents: retums to scale by intermediaries and bank runs.

The first approach draws upon the contributions of Bryant [1987] and Weil [1989] who emphasize the existence of multiple equilibria in one-shot games where the returns to savings by a representative agent is an increasing function of the average level of savings in the economy. In other words, these models assumed a "production externality" in the accumulation process, not unlike that used in Bryant [1983] and Baxter and King [1991].

\footnotetext{
I In eddition to our previous work, the pepern by Banudry and Devereux [1993] and Farmer and Guo [1994] aloo convidar the quamitentive

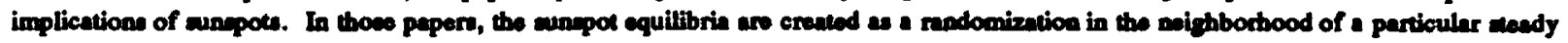

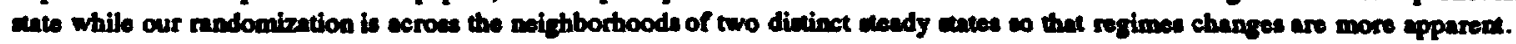

- This emphasia on ahocks to the process of aceumulation was previously explored by Greenwood, Hercowitz and Huffimnn [1988]. In our amalysis, we offer a different source for these hocks and relate the properties of the model to a different period of U.S. maeroeconomic history.
} 
A static example, along the lines of Bryant [1987] and Weil [1989], is to consider the savings decision of an agent who lives for 2 periods, consuming in both and endowed with the single good in the first period. Let $s\left(r^{d}\right)$ be the savings (deposit) function of the representative individual where $r^{d}$ is the real return offered by the intermediary. The numerous depositors simultaneously decide on the level of saving they direct to the intermediary. Denote by $S$ the aggregate flow of savings (deposits). The intermediary is competitive so that $r^{d}$ is the retum on investment. The critical assumption in the analysis is that $r^{d}$ is an increasing function of $S$. Thus the per capita level of savings is an increasing function of the aggregate level of savings through $s\left(r^{d}(S)\right)$. So, as in Cooper-John [1988], multiple symmetric Nash equilibria can arise.

While Bryant and Weil are not specific about the source of this returns to scale, one model of the increasing returns to scale comes from the role of intermediaries in the evaluation and monitoring of projects. Suppose that there are two types of investment projects. A fraction $\pi$ return $r>0$ with probability 1 and the remainder fail with certainty. Individual investors or the intermediary can choose to invest in projects without expending resources on ex ante project evaluation yielding an expected return of $\pi$. Alternatively, intermediaries can evaluate projects and select only those that will succeed. Assume that the costs of evaluation are described by a fixed cost $\mathrm{C}$. Then the returns, if evaluation occurs, per unit investment are $\mathrm{r}(1-(\mathrm{C} / \mathrm{S}))$. Clearly, there is a critical value of $S$ given by $S^{*}=\mathrm{C} /(1$ x) such that project evaluation is optimal iff $S \geq S^{*}$. Thus the returns to scale stemming from the fixed costs of project evaluation give rise to a return stream for an intermediary that 
is increasing in its level of activity. ${ }^{7}$

Moreover, switches across regimes have implications for the gap between deposit and loan rates. In an equilibrium with a low level of aggregate deposits, the gap between the loan rate (r) and the deposit rate ( $\pi)$ is (1- $\pi$ )r. In an equilibrium with a high level of deposits and thus project evaluation, the gap is $(\mathrm{C} / \mathrm{S}) \mathrm{r}$. From the conditions for an equilibrium with evaluation $(1-\pi)>(C / S)$ implying that the gap between loan and deposit rates falls in periods of high intermediated activity.

Instead of analyzing a model with increasing returns to the intermediary, consider the bank runs model of Diamond and Dybvig [1983]. This is essentially a static framework in which depositors decide, as a function of the choices of other current depositors, whether to withdraw their funds. The Diamond-Dybvig model provides conditions for fragility of intermediated investment when there is private information about the liquidity needs of depositors. ${ }^{8}$ This is a useful structure for thinking about bank runs during the Depression period as well as the optimism generated by the introduction of deposit insurance in 1934 . Fitting this bank runs model into our economy would require us to create a dynamic version of the Diamond-Dybvig model and to modify the stochastic growth model to allow for liquidity needs. Freeman [1988] accomplishes this by essentially requiring generational autarky while Fulghieri and Rovelli [1995] analyze the steady state of an economy in which intermediaries facilitate flows across generations within a 3-period overlapping generations models. Neither of these papers tackles the issue of analyzing bank runs in a dynamic setting

\footnotetext{
'Clearly this example is extreme in that there are no marginal cost of evaluetion and no consection effocts at all. Still, the precence of fixed conte of evaluation eem quite reasonable in that expertiec in cone project ovaluations aurely pillover to other ovaluations. 
in which the withdrawal choices of current depositors and the savings decisions of future generations would be jointly analyzed. A formal analysis along these lines is outside the scope of this paper. For our purposes, the loss of confidence in the intermediary will cause both current deposits to withdraw funds and future depositors to be pessimistic about intermediary. As a consequence, intermediaries will invest through a more liquid low return technology (see Diamond-Dybvig for a description of this choice) until confidence returns. Since returns are lower, so are deposits into the intermediaries. This model, which we have only outlined, appears to have a structure similar to the increasing returns model in that a financial crisis leads to lower flows through the intermediary and lower returns to depositors.

Our formal analysis explores the dynamic stochastic implications of the models proposed in Weil and Bryant by simply imposing increasing returns at the level of an intermediary. Moreover, we follow the lead of Boyd and Prescott [1986] by modeling the process of intermediation through the choices of a coalition of agents brought together each period. Boyd and Prescott stress the importance of incentives within the coalition while we focus on the implications of nonconvexities in the return stream of the intermediated activity. We have chosen to simplify our modeling of the financial sector to enable us to focus more thoroughly on the non-financial implications of the model.

Following the specification we considered in Cooper and Ejarque [1994], suppose that private agents can accumulate using either a low return, zero fixed cost technology or a high marginal return but positive fixed cost technology. The former represents a backstop technique for accumulation, representing the returns from poorly evaluated projects or

\footnotetext{
- Thus our model is entirely eelf-conlained in that there are no athitrary astumptions about behavior given this technology.
} 
perhaps a mattress full of fiat money. ${ }^{10}$ The latter is our representation of an active intermediation process involving the evaluation and monitoring of risky loans. The choice of these two techniques for accumulation is simply a convenient way to approximate the nonlinear return streams assumed by Bryant and Weil.

The economy is initially parameterized so that the strategic complementarity leads to multiple equilibria at all points in the state space. ${ }^{11}$ That is, regardless of the current level of capital, a representative agent will choose to accumulate through the intermediary if all other agents accumulate in this manner and, similarly, will use the less efficient technology if all others do. To obtain this result, we assume that the fixed cost of intermediation is relatively low if all others accumulate via the intermediary and is prohibitive if a single agent uses the intermediation technology. The first type of restriction gives an equilibrium with intermediation while the other gives an equilibrium with no intermediation. We then consider other parameterizations in which the multiplicity arises only in a subspace of the state space which leads, in our economy, to the existence of deterministic cycles.

The model is closed by assuming the existence of a sunspot process that coordinates the choices of agents on a particular outcome. Thus the coordination failure in this economy concerns the nature of the accumulation process rather than contagion effects in which a local run spreads throughout the economy..$^{2}$

Given that our agents are assumed to be identical and that the sunspot variable is

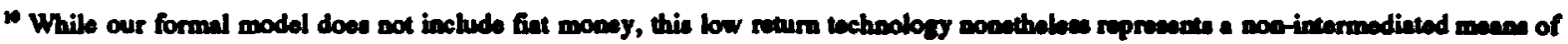
unanforming goods over tim which is evential to any toce of value.

"To be careful about verminology, these multiple equilibria are for a particular value of the tnte varible and thus pertin to multiplicity of equilibria in the ange game.

${ }^{12}$ See Smith [1991] for a diseunsion of contagion effocts.
} 
aggregate, the Nash equilibrium of this economy can be conveniently represented as the solution of a stochastic, dynamic programming problem. $V(k, \theta)$, the value function for a representative agent with capital $\mathbf{k}$ when the realization of the sunspot variable is $\theta$, solves:

$$
V(k, \theta)=\max _{I, n} U(f(k, n)-I, n)+\beta E_{\theta^{\prime} \mid \theta} V\left(g(I, \theta)+k\left(1-\delta_{k}\right), \theta\right\}
$$

where

$$
g(I, \theta)=\left\{\begin{aligned}
I(1+\tau) & \text { if } \theta=\theta_{p} \\
(I-F)(1+\bar{r}) & \text { if } \theta=\theta_{0} .
\end{aligned}\right.
$$

In this specification, the current utility payoff depends on current consumption of non-

durables and employment. Consumption of non-durables flows from current output less the investment in the accumulation of capital.

The evolution of the capital stock reflects the undepreciated stock plus the new flows. The effect of the sunspots, represented by $\theta$, comes into the problem through the accumulation equation, $g(I, \theta) \cdot{ }^{13}$ If $\theta=\theta_{p}$, depositors are pessimistic, deposit flows are low and the return from investment (in terms of future capital) is $(1+I)$. If $\theta=\theta_{0}$, depositors are optimistic and deposits flows are large enough that the coalition pays a per capita fixed cost of intermediation $(F)$ to obtain a marginal return $(1+r)$. Naturally, $r>r$ so that the marginal return on investment is higher in the technology with the fixed cost. ${ }^{14}$ Thus it is new investment flows into physical capital that are influenced by the current state of intermediation.

\footnotetext{
"Note that at this point the model is observationally equivalent to a model in which there are fundamentals driving the returns to intermedinted activities. We retum to the point of how one can distinguish these models later in our discuscion of confidence buildins measures.

14 The model deacribed earlier would have $(1+t)=1$ and $(1+t)=\pi$.
} 
To use this dynamic programming problem to study our economy, we need to establish the existence of a sunspot equilibrium. For this economy, Proposition 1 states that there exists a $V(k, \theta)$ which satisfies (1). Proposition 2 shows that for all $k$ in the relevant state space, there are multiple equilibria for small enough values of F. ${ }^{15}$ Proofs are provided in the Appendix.

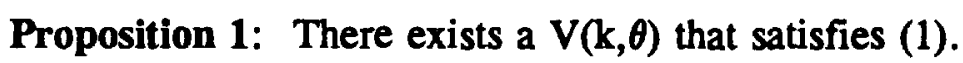

Proposition 2: There exists a value of $F$ such that $V\left(k, \theta_{p}\right) \neq V\left(k, \theta_{0}\right)$ for $k \in \kappa$.

Proposition 2 is the key result in terms of the multiple equilibria. The proof of the proposition identifies a critical value of the fixed cost (F) such that multiple equilibria exist in the static game for all values of $k$ in the relevant state space, $\kappa$. If $F$ is smaller than $F^{*}$, then multiple equilibria of the static game will still exist since an individual will choose intermediation over the alternative whenever the cost of intermediation is less than $F^{*}$. On the other hand, if $\mathbf{F}>\mathrm{F}^{*}$, there may exist parts of the state space in which intermediation is sub-optimal for any individual agent, regardless of the choices of others. In this case, the choice of the backstop technology is a dominant strategy and sunspots are irrelevant in this region of the state space. However, as we discuss below, cycles may emerge.

Before proceeding to the quantitative analysis, it is instructive to briefly look at the first order conditions of this problem, given by:

"Shere we limil the rate epace of capital to lie in the set $x$ which is the interval between $k_{j}^{*}$ and $k_{;}^{*}$ where $k_{j}^{*}$ atisfies $k_{j}^{*}=k^{\prime}\left(k_{j}^{*}, 0_{j}\right)$ for $j=0, p$. 


$$
\begin{gathered}
U_{1} f_{n}=-U_{2} . \\
U_{1}(c, n)=\beta E_{\theta \gamma_{\theta}} U_{1}\left(c^{\prime}, n\right)\left[f_{k}+\frac{(1-\delta)}{\left(1+r\left(\theta^{\prime}\right)\right)}\right](1+r(\theta)) .
\end{gathered}
$$

The first equation equates the marginal rate of substitution between consumption and work with the marginal product of labor and the second equation is the Euler equation. Since there are no productivity shocks in the economy and the capital stock is predetermined, the intratemporal condition implies that generally consumption and employment will move in opposite directions in response to, say, interest rate or wealth variations. ${ }^{16}$ Thus, not surprisingly, one issue that arises in an economy driven by intermediation shocks is the potential for a negative correlation between consumption and employment, a point we comment on in some detail below.

Further, from the Euler equation, we see that variations in the return to intermediation, both current and future, directly influence the accumulation decision. In particular, as the intermediation process becomes more productive, individuals will substitute toward future consumption and away from current consumption. This will tend to create a negative correlation between intermediated and non-intermediated activities and will become a central issue when we relate the implications of our model with observations. Note also, that variations in the returns to intermediation appear in (4) as shocks to the Euler equation. In some accounts of the Depression period, for example Hall [1988] and Temin [1976], there is an emphasis placed on unexplained variations in consumption which perhaps can be

\footnotetext{
1 This is a point put forth by Barro and King [1984] a an argument for why fluctuation mun entuil procyclical wage if preferences are time separable. A diecuased by Benhabib and Farmer [1994], if there are, for example, large externel returns to acale in the production function, then even with sepanble preferences, consumption and employment could become positively correlnted.
} 
attributed to changes in the returns to intermediation.

\section{Quantitative Implications}

Our quantitative analysis of this economy utilizes the policy function generated by the solution to (1). For the analysis, assume that $U(c, n)=\log (c)+v \log (1-n)$ and that the production function is Cobb-Douglas, $f(k, n)=k^{a} n^{1-\alpha}$. The parameter $v$ is set so that the fraction of time working in our economy is $20 \% .{ }^{17}$ Further set labor's share to .65 , which is consistent with observations over the $1920-40$ period. From Gordon and Veitch [1988], the annual rate of capital depreciation is $10 \%$ and the discount rate of the representative agent is set at .9. The differential in the marginal returns from the two accumulation technologies is set at $3 \%$, with $1+\mathrm{r}=1$ and $1+\underline{r}=.97 .^{18}$ Finally, we assume that the sunspot variable is highly serially correlated: $\operatorname{Prob}\left(\theta_{1+1}=\theta_{j} \mid \theta_{1}=\theta_{j}\right)=.9$ for $j=0, p$. Since the last component of our model is not directly tied to observations, we experimented with the robustness of our conclusions to variations in the transition matrix describing the sunspots and the interest rate gap. Our basic results did not change. ${ }^{19}$

The numerical approach is to discretize the state space for capital and the choice space for labor and, through value function iteration, characterize the solution to (1) as well

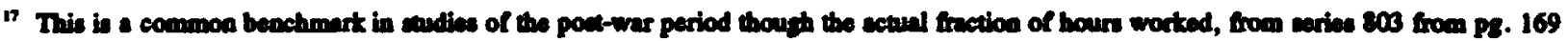

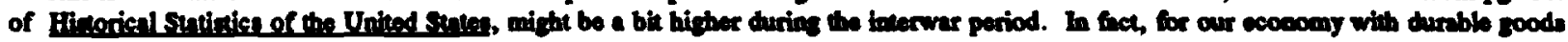
we rake a figure of $24 \%$ which is clower to obervation for the period under andy.

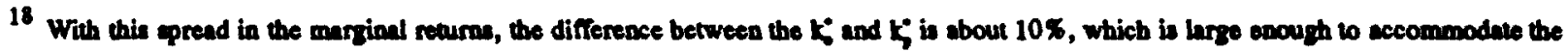
capital mock variation oberved during the Great Depreation.

19 We considered a cave in which the aunpots were id and another in which optimiem was more pertisent than peatimism. The resuhing policy functions were quite similar to thowe from the beseline model.
} 
as the associated policy functions. ${ }^{20}$ The policy functions, which determine the future capital stock and the level of employment given the realized value of the sunspot variable and the current capital stock, $k^{\prime}(k, \theta)$ and $n(k, \theta)$ respectively, form the basis for the simulations of the model. The properties of other relevant aggregate variables, such as consumption, output, productivity etc. are determined from these simulations.

From Figure 2a, the capital accumulation process implies that, for given $\theta$, increases in the current capital stock lead to higher future capital. Further, for a given current capital stock, the switch from non-intermediated to intermediated accumulation implies a higher level of the future capital stock. From Figure 2b, the employment level is a decreasing function of the $\mathrm{k}$ given $\theta$. This is a common feature in the stochastic growth model (see King, Plosser and Rebelo [1988] for a detailed discussion) and reflects the response of employment to changes in the interest rate as capital is accumulated. Note too that as the returns to accumulation increase, so does employment: $n\left(k, \theta_{\partial}\right) n\left(k, \theta_{p}\right)$ for all $k$.

Figures 3-5 illustrate various series from 100 periods of a 2000 period simulation of the model economy. From Figure 3, the path of the aggregate variables reflect two forces. The first is the infrequent shifts in the sunspot variable associated with changes in the accumulation process. Within a regime, the second force is the transition to the statecontingent stationary level of the capital stock. The interaction between the transition and the regime shifts creates the complex dynamics displayed in the figures and the pattern of correlations discussed below. When there is a regime shift, say from $\theta_{\mathrm{p}}$ to $\theta_{\mathrm{o}}$ as in period 121 , investment increases to take advantage of the high returns to accumulation while

\footnotetext{
20 The atute apace for capital has 471 elements and there are 91 choices for labor. The choice apace was not restrictive in the cence that choices were not at the boundaries.
} 
consumption is temporarily reduced to finance investment. During the subsequent accumulation process (displayed in Figure 3), consumption rises and investment falls (as in Figure 4). Further, hours worked initially rises when the state changes to $\theta_{0}$ and then fall as capital is accumulated, reflecting the decrease in real returns.

Two rates of return for the economy are displayed in Figure 5. One is the ex post return on loans given by $R=f_{k}+\left((1-\delta) /\left(1+r\left(\theta^{\prime}\right)\right)\right.$. This is the lending rate of the intermediary in terms of future output. A second is the average return from the intermediary, $r^{d} \equiv R(1-F(\theta) / I)(1+r(\theta))$ where $I$ is the per capita investment level and $F(\theta)$ is the fixed cost of intermediation when the current state is $\theta .^{21}$ This is a deposit rate for the coalition of agents forming the intermediary. Note that both returns are countercyclical. So, for example, the increase in $r(\theta)$ as the economy goes from pessimism to optimism, reduces the value of undepreciated capital which forces $\mathbf{R}$ down. The consequent rise in the capital stock lower $f_{k}$ so that $R$ continues to fall. From the figure, it is also apparent that the gap between lending and deposit rates is countercyclical, reflecting the greater productivity of the intermediation process during periods of optimism.

Table 1 presents basic statistics from this 2000 period simulation for these real (in logs) and financial variables. ${ }^{22}$ The calculations in the first row of the table are for the entire simulation period and hence ignore the fact that regime switches occur during the experiment. Thus the statistics reported here pertain to the movement of variables both

\footnotetext{
${ }^{21}$ Of coure, $F(O)=0$ when $\%$, is realized. This is not a marginal rewrn on incermedintion but is the avernge return if the intermedingy liquidates its holdings afler 1 period and each agent inverts, in the cymmetric equilibrium, the ame lovel I.

2 The variblea are: conmuption (C), hours (I), Invectmen (I), Prod (average labor productivity), $\mathbf{R}$ (lending rate) and f(reurn on intermediated deposits). Note that $I$ is defined here as output less conamption. The behnvior of inveutment net of the fxed intermediation cout is not very difierent from the meanre reported here.
} 
within and across regimes. The second and third rows of the table perform the appropriate sample split so that these statistics capture the behavior of aggregate variables within the two regimes.

From these correlations and other statistics, note that the predictions of this model are quite similar, in many respects, to the statistics produced by real business cycle models in which fluctuations are driven by technology shocks. Over the entire sample period, we see that the major aggregate variables are all positively correlated with output and productivity is procyclical. Further, the model displays consumption smoothing in that consumption is less volatile than output. Note too that investment, measured here as output less consumption, is more volatile than output. ${ }^{23}$ Finally, the economy exhibits serial correlation in output close to 1 due to the serially correlated shocks to beliefs and the dynamics of the adjustment process. $^{24}$

There are some aspects of the simulated data which, as we discuss below, do not match up with observation. First, the capital stock has a standard deviation of about 2.5 times that of output. ${ }^{25}$ Second, consumption and investment are negatively correlated $(-.30)$ as are consumption and hours (-.45).

From the figures presented earlier, it is clear that these correlations reflect both changes in regimes and the transition of the economy within a regime. The other rows of Table 1 present the statistics for our simulated economy when we split the sample by regime.

\footnotetext{
25 This is also true if we meanure inventment as net of the fixod conte of intermediation.

4h Cooper and Ejarque [1994] report that in a linearized economy with iid istermediation shocks, the serial correlation in ourpun is abour .75.

2s The careful reader will note though that our capiul includes in it variations in returns to inventmenc and thus is different from the unul measures of the capital atock generated by adding inventment flows to an undepreciated mock. We can reproduce this ahernative maanure of capital in our aimulatione and we mill find that the atandand devintion of capital far exceods that of output.
} 
Note that the patterns of comovements change dramatically. In particular, consumption and investment move in opposite directions within a regime. At the time of a regime switch to active intermediaries, there is a burst of investment that is partially funded by a temporary decline in consumption. As the capital accumulation proceeds, investment falls and consumption and output both rise. Further, output and hours move in opposite directions as well, which is evident from the intratemporal optimization condition. Thus a model with regime changes has implications for the data within a particular regime that can be quite different from the observations across regimes.

A key component of the parameterization was the choice of the fixed cost, F. For these simulations, $\mathrm{F}$ was sufficiently small that, following Proposition 2, there was a multiplicity of equilibria at all points in the capital state space. ${ }^{26}$ Suppose instead that the fixed cost was increased so that for low levels of investment, accumulation through the intermediary was undesirable even if all other agents saved in this fashion. In this case, sunspot equilibria might arise in only a subset of the state space. Since low levels of investment occur in the neighborhood of the state-contingent steady states, sunspot equilibria near the optimistic steady state may disappear. ${ }^{n}$

Figure 6 displays the capital policy functions, $k^{\prime}(k, \theta)$ for $\theta=\theta_{0}, \theta_{p}$, for a value of the fixed cost that is a multiple of the value used before. The pessimistic policy function is similar to that displayed in Figure 2a. Note though that the optimistic policy function jumps at a capital stock below $k_{0}^{*}$, where $k_{0}^{*}$ is the optimistic steady state determined by

\footnotetext{
* This propenty was confirmed as part of our simulation by computing the returns to inverting in auch of the wechoologies.

27 Here we aseocinle aunopot equilibria with the confidence of agents in the intermediation procesu rather than with their choice of eccumulation technology.
} 
$\mathbf{k}_{0}^{*}=\mathbf{k}^{\prime}\left(\mathbf{k}_{0}^{*}, \theta_{0}\right)$. The break occurs because investment, which is a decreasing function of $\mathbf{k}$, is sufficiently low for $\mathbf{k}$ near $\mathrm{k}_{0}^{*}$ that it is not worthwhile to pay the fixed intermediation cost regardless of the choice of others. Thus, even though agents are optimistic, they nonetheless choose to save through the non-intermediated technology. This jump in the capital policy function produces a cycle in our economy. ${ }^{28}$

\section{Macroeconomic Reality}

Our goal in this section of the paper is to provide evidence on the behavior of key macroeconomic variables in the interwar period (1921-41) with particular emphasis on the Depression period. We use these statistics to evaluate our model and more generally to examine the question of whether the interwar and post WWII periods differ.

\section{A. Real Variables}

Table 2 provides basic statistical information on U.S. macroeconomic aggregates for different historical periods. For this row, consumption is purchases of non-durables and services and investment is gross fixed investment. The first row is taken mainly from King, Plosser and Rebelo [1988] and summarizes post WWII data. To compute these statistics, the raw data was converted to logs and then linearly detrended. The statistics reflect the well understood patterns of business cycles: consumption smoothing relative to output, investment more volatile than output, persistent fluctuations in output and positive correlation of all variables with output. Further, for this period, the correlation of consumption and investment is positive and the standard deviation of the capital stock is less than that of

\footnotetext{
20 Azariadis and Smith [1994] aleo provide an example of an endogenous cycle in the intermodiation proceas. In their ecosomy, there is a moral hezard problem whoce severity depends on the state of the syntem. For low values of the capitul tock, the incentive constraints asaciated with the moral bazard problem ane not binding and the economy accumulates capital. For high valuea of capital, the incentives to cheal are atronger and incentive constraints bind. For their oconomy, this leads to a cycle.
} 
output.

The second row of Table 2 uses an alternative data set created from Kendrick [1961]. Here the data is annual and covers the period $1921-41 .{ }^{29}$ Figure 7 plots real output, consumption (excluding durable expenditures) and investment (excluding inventory changes) over this period. The positive comovement of these series is evident from both the figure and the table. Further, note from the table that the capital stock is less volatile than output over this period.

With regard to productivity, Kendrick [1961] provides an exhaustive study of the patterns of productivity, including the interwar years. Figure 8 plots total factor productivity and output obtained from Kendrick [1961] ${ }^{30}$ The procyclical nature of productivity is quite clear: between 1929 and 1933, the total factor productivity index fell about 12\%. More recently, Bernanke and Parkinson [1991] confirm this finding of procyclical productivity in 10 U.S. manufacturing industries during the 1923-39 period. This result, they argue, casts doubt on the role often ascribed to total factor productivity shocks in explaining aggregate fluctuations unless one argues that the Depression was a consequence of technological regress. ${ }^{31}$ Instead, the procyclical nature of productivity could reflect labor hoarding or some form of increasing (external or internal) retums to scale.

Relative to the entire interwar period, the Depression period does not stand out as a

\footnotetext{
2 The den for output, conumption and inverment is from Table A-II, the data foc capital (private non-furm) is from Table A-XV asd

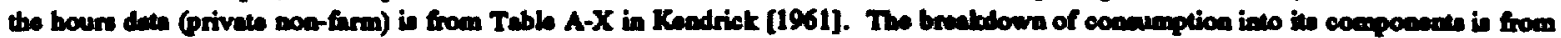

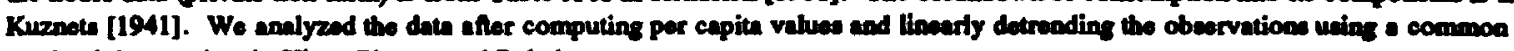
productivity trend an in Xing, Flower and Robelo.

so Average labor productivity is aleo procyclical over this period.

"Bernanke and Partineon argue trongly egainst the view that exogenouv variations in total factor productivity were the chuse of the Deprescion though they recognized that ober real factors (wch as the productivity of the intermediation procese) may be inportan. The iseve, of cource, is to link these other "real shocks" to the observed procyclical productivity.
} 
time in which the behavior of the macroeconomy, characterized by the few basic statistics presented here, was obviously different than the post WWII or interwar periods. Of course, the magnitudes of changes in these variables was quite large during the Depression period relative to the latter period.

B. Financial Variables

The financial events of the Depression were the motivating features of this study and were extensively documented in the historical study by Friedman and Schwartz [1963]. Bernanke [1983] and Mishkin [1978] also stress the importance of financial factors for firms and households. The main features of the financial sector during this period are the bank runs starting in October 1930 and ending in March 1933. Associated with these runs were dramatic changes in the currency/deposit ratio and the loan/deposit ratio. As documented in Friedman and Schwartz [1963,Chart 31], the deposit/currency ratio fell from 11.57 in October 1929 to a low of 4.4 in March 1933. The loan/deposit ratio fell from .86 in October 1929 to a low of .44 in August $1934 . .^{32}$ Bernanke [1983, Table 1] documents the substantial contraction in commercial bank loans over the Depression period. In October 1931 , for example, the reduction in loans was about $31 \%$ of personal income.

In addition, the behavior of interest rates is quite important during this period. As documented in Friedman and Schwartz [1963] and Bernanke [1983], a sizeable gap emerged in the Depression period between the returns on relatively risky corporate debt and government securities. This is often viewed as a consequence of the flight to quality by lenders. Further, from Hamilton [1987], real interest rates rose during the Depression

The figures are from Table 48 from Bankine and Monetary Stutizic: 1914194], Board of Governors [1943]. 
period.

Of particular importance to our model of financial instability are the steps taken to restore confidence in the banking system. The Banking Act of 1933 contained the main element that led to renewed confidence in the banking system: deposit insurance. As argued by Friedman and Schwartz [1963,p.434],

"Federal insurance of bank deposits was the most important structural change in the banking system to result from the 1933 panic, and, indeed in our view, the structural change most conducive to monetary stability since state bank note issues were taxed out of existence immediately after the Civil War."

V. Evaluating the Model

A. Interwar period

The first means of evaluating our model comes from a comparison of the behavior of the artificial economy summarized in Table 1 with the data given in Table 2. We then turn to our own account of the Depression period.

How well does our model do in matching the basic features of the data? Comparing the first row of Table 1 with the second row of Table 2, the pooled data from our simulated economy is broadly consistent with observations on consumption, hours and investment. In particular, our model displays consumption smoothing, procyclical employment and investment which is more volatile than output. In fact, our investment series has a fairly large standard deviation relative to output (compared to, say, the simulated moments reported for the real business cycle model in King, Plosser and Rebelo) which is in accord with observations for the interwar periods. 
As noted earlier though, the negative correlations between investment and consumption and between hours and consumption are not found in the interwar data. Further, the capital stock is less volatile than output for both the interwar and post WWII periods.

One possible explanation for these differences is that other factors, such as total factor productivity (tfp) shocks, might also be influencing the economy and thus creating some of the positive correlation observed. That is, perhaps we are asking too much of our model to have it explain the entire interwar period through a single regime shift in the 1929-34 period. To deal with this issue, we extract both tfp and the capital from the consumption and investment series, using the calibrated model of King, Plosser and Rebelo, and look at the correlations of the residuals. ${ }^{33}$ We find that the residuals of consumption and investment are negatively correlated $(-0.21)$ over the interwar period.

For our economy, we have neither labor hoarding nor increasing returns to scale in our theory model. Thus, in our economy there should be no fluctuations in total factor productivity. In both economies, average labor productivity is positively correlated with output when the observations are pooled across regimes. Within regimes, when the intermediation process collapses, the capital stock falls, output falls and the real interest rate rises along the transition to $k_{p}^{*}$. During this adjustment process, employment is higher and hence average labor productivity is lower. Thus, we tend to obtain the prediction of procyclical productivity within a regime because hours are not positively correlated with output.

\footnotetext{
w As in the discuscion of Figure 1, the point is to see whether the fluctuntions in the variables that remain after extmeting the influence of a real busines cycle model have propertiea that conform to our model.
} 
With regard to the financial facts listed earlier, our intent was to construct a model which captured these basic features of financial data and then to evaluate its implications for real variables and other financial variables. Thus, our pessimistic equilibrium, in which savings is not intermediated and has a low return, captures both the substitution of savings away from intermediaries (the increased currency/deposit ratio) and the relative inefficiency of the intermediation process (the fall in the loan/deposit ratio). It is certainly true that the actual financial collapse was less severe than the pessimistic outcome of our model in which there is no intermediated savings. This is partly an issue of interpretation since the nonintermediated technology could be intermediated accumulation through a set of relatively high-risk, low-retum loans. Further, one might be able to extend the model to allow for some heterogeneity with regard to deposit decisions so that pessimism is associated with low, rather than zero, levels of activity. As noted earlier and displayed in Figure 5, a gap does occur in our model between loan and deposit rates which is greater in periods of low intermediation activity due to higher default rates. ${ }^{34}$

Last, but not least, our theoretical model stressed non-linearities arising from regime shifts. Thus one way to evaluate that model is to search for regime shifts over this period and see whether they correspond to drastic changes in financial market activity. Cooper and Durlauf [1993] analyzed the behavior of industrial production over the 1923-91 period and do find regime splits within the sample period, particularly in the interwar period..$^{35}$

Coe [1995] tests a regime shift model for the interwar period using a three state

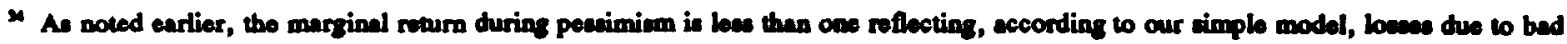
loans.

s See aleo Dagevik and Jovanovic [1991].
} 
Markov process, along the lines of Hamilton [1989], to analyze the behavior of the depositcurrency ratio and a "default premium", measured as the gap between the yield on long term government bonds and "risky" corporate bonds. In contrast to our two-state sunspot model, Coe allows for three states: calm, crisis and collapse. He finds that a state of financial crisis first began in late 1930 . While in late 1932 and early 1933 there was some movement back to financial calm, it was not until early 1934 that financial stability was restored. Interestingly, these regime shifts fit the period of bank runs starting in late 1930 rather than the stock market crash of late 1929.

Complementary to these findings, we have analyzed the linearly detrended per capita series created from the data reported in Kendrick [1961] by allowing for a regime shift in each of the three series. Following Coe, we first tested for a regime change over the 193133 period. We rejected the hypothesis of a regime change for output and investment and could not reject the hypothesis of a regime shift in consumption. ${ }^{36}$ We then broadened our search for regime shifts and could not reject a regime change over the 1932-35 period for all three series. ${ }^{37}$ For all of these regressions, the coefficient on the regime in the investment equation was quite large in absolute value relative to the coefficients in the output and consumption equations. This is consistent with our theory in that, as illustrated in Figure 4, swings in investment are quite pronounced at the time of a regime shift.

From the perspective of our model, the introduction of deposit insurance can be interpreted as a regime shift in which pessimistic beliefs are replaced by optimism around

\footnotetext{
"For invertment and output, the coeficien on the regime variable was negative (the dummy was set at 1 during the crisis) but had $t-$ antixtics below 1.3. Por conumption, the coeficient on the regime variable wa significanly negative.

37 Further, we cannot reject a breat from the 1929-33 period uaing a Wald teat for the joint aignificance of the regime change dummiea on coneumption, inveatment and output.
} 
1934. From Figure 7, we see that 1933 was certainly the low point of the Depression: output, consumption and investment all rose from 1933 to the downturn of 1937. Data from Kendrick [1961] indicates that the capital stock hit a low in 1935. These observations are consistent with the predictions of our model: following a regime shift, the capital stock, consumption and output should all rise together.

It should be noted that the behavior of investment in our model is much more responsive than in the data. From Figure 4, a shift from optimism to pessimism causes a huge drop in investment and then investment starts to increase even within the pessimism regime. Likewise, the model predicts a large investment burst at the start of optimism. These dramatic movements in investment across regimes is not apparent in the data, perhaps reflecting some costs of adjusting the capital stock too rapidly.

Finally, it is worthwhile to consider the point made earlier that a competing interpretation of our model associates fundamental shocks to the intermediation process instead of the sunspot process studied here. While it is true that these models are observationally equivalent, it seems natural to us to associate both the bank runs in the early 1930s and the financial calm that arose following the bank holiday in 1933 as reflecting changes in confidence. Otherwise, one must argue that there are apparent changes in the technology of the intermediation process that occured during this period. ${ }^{38}$

B. Other countries and times

Building on Bernanke [1983], Bernanke and James [1991] study the importance of financial disruptions in determining the output of other countries in the interwar period. As

\footnotetext{
${ }^{38}$ Nole that the nonlinearities we uncover cannol be due to variations in the Solow residual since that has been taken into eccount in the regresuion analysis.
} 
summarized in their Table 2.7, many other European countries experienced banking crises, such as runs, between 1929 and 1936. Using a panel of 21 countries over the 1930-36 period, they find that dummy variable for financial panics is quite large and highly significant. While it is beyond the scope of this paper to use our model to study these other economies in detail, the analysis of Bernanke and James does highlight the point that "regime shifts" were not exclusively experienced in the U.S.

Moreover, the 1930-33 period was certainly not the only time of financial crisis in the U.S. As discussed by Friedman and Schwartz [1963], the U.S. experienced a number of major banks runs during the 1870-1930 period. Williamson [1989] provides some evidence linking these panics in the U.S. to detrended U.S. output over the 1870-1923 period. Williamson reports that the correlation between bank failures and output is about -.25 . Again, looking for regime shifts during these periods and exploring the comovement of other macroeconomic variables would be of considerable interest.

C. Extensions of the Basic Model

Overall, the models of financial fragility constructed in this paper capture some but not all of the behavior of the U.S. economy during the interwar period. There are two aspects of the model that are inconsistent with observation over the entire interwar period: the negative correlation between consumption (or at least a component of it) and investment and the excessive volatility of the stocks of durables and capital predicted in the model. These features arose in Cooper and Ejarque [1994] as well for many of the reasons suggested by Greenwood, Hercowitz and Huffman [1988]. Part of the purpose of the present paper was to see if these aspects of the models were consistent with observations during the 
interwar period since the other papers had focused on the post WWII period. We now discuss two modifications of the paper that may help to deal with these problems. ${ }^{39}$

\section{Durable Goods}

The economy we have studied so far misses an important element in the interaction between financial variables and real economic activity. In particular, durable consumption is a very volatile element of consumption and is generally responsive to financial conditions. ${ }^{40}$ This is certainly true for housing purchases but also for the purchase of many consumer durables, particularly automobiles. In fact, during the years prior to the Depression period, a significant fraction of automobile purchases were through credit arrangements.

Moreover, with regard to the behavior of consumption, it is constructive to consider more disaggregated measures of these flows by distinguishing durables from non-durables and services. From Kuznets [1941], there is some evidence that the components of consumption did not move together over the Depression period. In 1930, the consumption of services rose while other expenditures (durables, semi-durables, perishables) all fell. In 1934, durables expenditures started to rise again while expenditures on services first rose in 1934 and then fell in the two subsequent years.

Figure 9 plots the fraction of consumer durable purchases relative to total consumption over the 1922:41 period from Balke and Gordon [1988]. From the start of the Depression, the consumer durable share fell from about $10 \%$ to less than $6 \%$. To the extent that consumer durable purchases might be intermediated and thus responsive to financial

\footnotetext{
- For these additional treatmenes, the parameters ane the same as thowe in the baseline model reporied earlier.

* Gondon and Veitch [1986] also emphanize the important role of coneumer durablea.
} 
conditions, this type of substitution across components of consumption might be a consequence of financial crises.

Further evidence on this substitution is provided by Romer [1990] who investigates the behavior of components of consumption during late 1929 and early 1930 . She reports that durable purchases, such as automobiles, fell considerably during the early part of the Depression while spending on non-durables, such as food, actually rose in late 1929.

To introduce durables goods into our economy, consider a utility function given by $\mathrm{U}(\mathrm{c}, \mathrm{d}, \mathrm{n})=\log (\mathrm{c})+v_{\mathrm{d}} \log (\mathrm{d})+v_{\mathrm{n}} \log (1-\mathrm{n})$ where $v_{\mathrm{d}}$ and $v_{\mathrm{n}}$ are parameters. We use observations on the average level of purchases of nondurable consumption goods and services to expenditures on durables from Balke and Gordon [1988] to parameterize $v_{d}$. Durable services were proportional to the stock of durable goods. To simplify our computations, we maintain the assumption of a single capital good but allow it, in each period, to be either used as a durable consumption good or as an input in the production function. ${ }^{41}$ For this problem, Bellman's equation is given by:

$$
V(k, \theta)=\max _{I, n, \gamma} U(f(\gamma k, n)-I,(1-\gamma) k, n)+\beta E_{\theta^{\prime} \mid \theta} V\left(g(I, \theta)+k\left(1-\delta_{k}\right), \theta^{\prime}\right)
$$

where

$$
g(I, \theta)=\left\{\begin{aligned}
I(1+\tau) & \text { if } \theta=\theta_{p} \\
(I-F)(1+\bar{r}) & \text { if } \theta=\theta_{0} .
\end{aligned}\right.
$$

where $\gamma$ is the fraction of the capital stock used in the production function. Thus this economy allows an agent to shift resources between physical capital and durables after the

\footnotetext{
4I an earlier verion of this paper we explored an economy with two tate variablen but due to compunational limilations have choeen the single tate variable approach here.
} 
realization of the sunspot. As before, the fixed cost is set so that sunspots arose throughout the state space and the value function iteration procedure converged. ${ }^{42}$

As with our earlier economy, future capital is an increasing function of $\mathbf{k}$ and employment is a decreasing function of $\mathbf{k}$. Further, both $\mathbf{k}^{\prime}$ and $\mathbf{n}$ are, as before, increasing in $\theta$ given $\mathbf{k}$.

The economy was simulated for 2000 periods and the results are summarized in Table 3. As before, we present statistics for the entire sample and by regime. For entire sample of this economy, many of the features of the previous one without durables remain: the main aggregate variables are all positively correlated with output, the consumption of nondurables is smoother than output and investment is more volatile than output. Further, as in the economy without durables, the capital stock is more volatile than output: the standard deviation of (log) capital relative to (log) output is 2 .

Of particular interest is the behavior of consumption and investment. Recall that in the economy without durable goods, consumption and investment were positively correlated with output but negatively correlated with each other. For the economy with durable goods, the correlation between the consumption of non-durables and expenditures on durables is about -.09 . Durable consumption expenditures and investment are positively correlated (.74) while non-durable consumption remains negatively correlated with investment $(-.21)$.

These correlations do not accord with observations since, as noted earlier, all components of consumption are positively correlated with each other and with investment

\footnotetext{
- We do not present excenelone to Propoditions 1 and 2 for this more generd economy. A proof of the exictence of a solution to the more complex dynamic prognmmins problem is relatively anightforward. Our chaneterization of annepot equilibris for our particular economy is achieved by checking that intermediation is preferrod to non-intermediated accumulation at anch point in the ante apace.
} 
over the entire interwar period. Yet, the model does contain some of the properties observed in the data, in particular the possibility of substitution between intermediated and non-intermediated activities. From our simulations, at the time of a regime change, the components of consumption tend to move in opposite directions. So, at the onset of the Great Depression, our model would predict the observed increase in expenditures on some non-durables and services and the reduction in durable expenditures.

\section{Capacity Utilization}

Greenwood, Hercowitz and Huffman [1988] dealt with the problem of negatively correlated consumption and investment by introducing a capital utilization choice. In their model, the rate of capital depreciation was influenced by its use thus setting up a non-trivial choice of utilization. So, in periods of low intermediation returns, a producer may reduce capital utilization to avoid having to use the relatively inefficient intertemporal technology for the production of capital in the future.

We have experimented with adding this choice to our sunspot economy using the same specification proposed by Greenwood, Hercowitz and Huffman. In particular, the producer selects the rate of utilization $\gamma$ so that the flow of capital services (for a given stock $\mathrm{K})$ is $\gamma \mathrm{K}$. The depreciation rate is determined by $\delta=\eta\left(\gamma^{\mu / \omega} / \omega\right)$ so that we have two additional parameters to choose. We impose the restriction that the average level of depreciation is $10 \%$ as in the data, set the average utilization rate at .9 and use the first order condition for capital utilization to set these parameters.

Allowing for the choice of capacity utilization did not dramatically affect our results. For the case of $10 \%$ depreciation and $\beta=.9$ (our baseline), we still find that consumption and 
investment are negatively correlated, consumption and hours are negatively correlated and that the capital stock is more volatile than output. These implications hold for even larger average depreciation (20\%), a higher discount rate of .96 , iid sunspots and more curvature in utility than the $\log$ case. ${ }^{43}$

\section{Conclusion}

Our goal is this paper was to explore the U.S. Depression from the perspective of a model of financial fragility. The model stressed the interaction of depositors in determining the nature of the intermediation process. As a consequence of a non-convexity in the intermediation process, a market participation externality was created which led to multiple equilibria for all points in the state space. This gave us a tractable model of sunspot equilibria in which extrinsic uncertainty correlated the actions of the agents. Our goal was to capture various aspects of financial instability such as runs and crashes in this framework.

In many ways, our models are quite consistent with observation. Many of the basic features of business cycles emerge in our economies if the data is pooled across regimes. However, there are two elements of the model which are at variance with observation: the negative correlation between investment and consumption (at least non-durables) and the excessive volatility of some capital measures. In the absence of movements in total factor productivity, these features of the model are not surprising and some remedies were explored.

\footnotetext{
"Greenwood, Hereowitz and Hufiman do not report the consumption investment correlation for their oconomy though they argue that for the preferences they epecify (no income effectu) that thin correlation is positive. They aleo do not report the relative thandand deviation of capital to output. Nole that our results on the exceas volatility of the capilal stosk hold even if, as mentioned previoualy, we compute the capital atock using NIPA conventions.
} 
One surprising aspect of the analysis is the similarity in the basic patterns of U.S. macroeconomic behavior during the interwar years and the post WWII period. Originally we had conjectured that many of the properties of our model (such as the negative correlations and the excessive volatility) might correspond to actual observations during the Depression since this experience was unlikely to be the consequence of total factor productivity variations. Picking up on a theme from Bernanke and Parkinson [1991], it is quite interesting that the economy behaves as if it was hit by a productivity shock though it is difficult to imagine that this is the case. Thus, understanding the basis for these total factor productivity movements is critical for interpreting the interwar period and for evaluating models of more recent behavior of the aggregate economy. Our analysis highlights two possible sources of measurement error that might create the appearance of procyclical total factor productivity: mismeasurement of capital and capacity utilization.

In Cooper and Ejarque [1994], we introduced a form of external returns to scale following the contribution of Baxter and King [1991] into an intermediation model. The idea in doing so was to create an endogenous increase in productivity during periods of high economic activity. Further, as discussed in Baxter and King, if the external effects are large enough, it is possible to create procyclical productivity and positive correlations between consumption and investment in economies with taste shocks." Thus, the introduction of these complementarities seems to be a useful approach to improving the ability of the model with financial intermediation shocks to match the data. However, for empirically reasonable levels of this external effect and a linearized economy, Cooper and Ejarque [1994] found that

\footnotetext{
"Of courne, for large enough values of the externalities, the anbility properties of the economy may change as exhibiled in Benhabib and Farmer [1994].
} 
consumption and investment remained negatively correlated and that the capital stock was still more volatile than output.

As for our regime switch approach, the model succeeds in capturing the dramatic shifts in the economy associated with the start of the banking crisis. Moreover, the renewal of confidence in the financial intermediation system stemming from government action in late 1933 and 1934 is easily modeled as another regime shift. A more complete analysis of the non-linear behavior of the economy over this period would be a productive next step in this type of research. 


\section{References}

Azariadis, C. and B. Smith, "Financial Intermediation and Regime Switching in Business Cycles," mimeo, September 1994.

Balke, N. and R. Gordon, "Appendix B: Historical Data" in The American Business Cycle: Continuity and Change, ed. by Robert Gordon, Chicago: University of Chicago Press, 1986, 781-850.

Barro, R. and R. King, "Time-Separable Preferences and Intertemporal-Substitution Models of Business Cycles," Quarterly Joumal of Economics, 99 (1984), 817-40.

Baxter, M. and R. King, "Productive Externalities and the Business Cycle," Institute for Empirical Macroeconomics, Discussion Paper \#53, November 1991.

Beaudry, P. and M. Devereux, "Monopolistic Competition, Price Setting and the Effects of Real and Monetary Shocks," mimeo, 1993.

Benhabib, J. and R. Farmer, "Indeterminacy and Increasing Returns," Joumal of Economic Theory, 63 (1994), 19-41.

Bernanke, B., "Nonmonetary Effects of the Financial Crisis in the Propagation of the Great Depression," American Economic Review, 73 (1983), 257-76.

Bernanke, B. "The Macroeconomics of the Great Depression: A Comparative Approach," NBER Working Paper \#4814, August 1994.

Bernanke, B. and M. Gertler, "Agency Cost, New Worth and Business Fluctuations," American Economic Review, 79 (1989), 14-31.

,"Financial Fragility and Economic Performance," Quarterly Joumal of Economics, 105 (1990), 87-114.

Bernanke, B. and H. James, "The Gold Standard, Deflation, and Financial Crisis in the Great Depression: An International Comparison," in Financial Markets and Financial Crises ed. by R. Glenn Hubbard, University of Chicago Press: Chicago, 1991.

Bernanke, B. and M. Parkinson, "Procyclical Labor Productivity and Competing Theories of the Business Cycle: Some Evidence from Interwar U.S. Manufacturing Industries," Loumal of Political Economy, 99 (1991), 439-59.

Boyd, J. and E. Prescott, "Financial Intermediary Coalitions," Loumal of Economic Theory, 38 (1986), 211-232. 
Bryant, J., "A Simple Rational Expectation Keynes-Type Model, " Quarterly Joumal of Economics, 97 (1983), 525-529.

"The Paradox of Thrift, Liquidity Preference and Animal Spirits, " Econometrica, 55 (1987), 1231-36.

Calomiris, C. "Financial Factors in the Depression," Joumal of Economic Perspectives, 7 (1993), 61-86.

Chatterjee, S., Cooper,R. and B. Ravikumar, "Strategic Complementarity in Business Formation: Aggregate Fluctuations and Sunspot Equilibria," Review of Economic Studies, 60 (1993), 795-811.

Chatterjee, S. and D. Corbae, "Endogenous Market Participation and the General Equilibrium Value of Money," Journal of Political Economy, 100 (1992), 615-46.

Coe, P. "Financial Crisis and New Deal Financial Reform During the Great Depression," mimeo, University of British Columbia, 1995.

Cooper, R. and A. John, "Coordinating Coordination Failures in Keynesian Models," Quarterly Journal of Economics, 103 (1988)441-64.

Cooper, R. and J. Ejarque, "Financial Intermediation and Aggregate Fluctuations: A Quantitative Analysis," NBER Working Paper \#4819, August 1994.

Dagsvik, J. and B. Jovanovic, "Was the Great Depression a Low-Level Equilibrium?" NBER Working Paper \#3726, 1991.

Diamond, D. "Financial Intermediation and Delegated Monitoring," Review of Economic Studies, 51 (1984), 393-414.

Diamond, D. and P. Dybvig, "Bank Runs, Deposit Insurance and Liquidity," Loumal of Political Economy, 91 (1983), 401-19.

Diaz-Giménez, J., E. Prescott, T. Fitzgerald and R. Alvarez,"Banking in Computable General Equilibrium Economies," Joumal of Economic Dynamics and Control, 16 (1992), 533-59.

Farmer, R. and J.T. Guo, "Real Business Cycles and the Animal Spirits Hypothesis," Joumal of Economic Theory, 63 (1994), 42-72.

Fisher, J., "Credit Market Imperfections and the Heterogenous Response of Firms to Monetary Shocks," Research Report 9410, University of Western Ontario, May 1994. 
Freeman, S. "Banking as the Provision of Liquidity," Loumal of Business, 61 (1988), 45-64.

Friedman, M. and A. Schwartz, A Monetary History of the United States, 1867-1960. Princeton University Press: Princeton, N.J., 1963.

Fulghieri, P. and R. Rovelli, "Capital Markets, Financial Intermediaries and Liquidity Supply," mimeo, Kellog Graduate School of Management and IGIER, 1995.

Garcia, R. and P. Perron, "An Analysis of the Real Interest Rate Under Regime Shifts," mimeo, Universite de Montreal, February 1993.

Gertler, M., "Financial Structure and Aggregate Economic Activity: An Overview," Loumal of Money, Credit and Banking, (1988), 559-88.

Gordon, R. "Introduction, " in The American Business Cycle: Continuity and Change, ed. by Robert Gordon, Chicago: University of Chicago Press, 1986, 1-33.

Gordon, R. and J. Veitch, "Fixed Investment in the American Business Cycle, 1919-83," in The American Business Cycle: Continuity and Change, ed. by Robert Gordon, Chicago: University of Chicago Press, 1986, 267-340.

Gorton, G. "Banking Panics and Business Cycles," Oxford Economic Papers, 40 (1988), 751-81.

Greenwood, J., Z. Hercowitz and G. Huffman, "Investment, Capacity Utilization and the Real Business Cycle," American Economic Review, 78 (1988), 402-17.

Greenwood, J., Z. Hercowitz and P. Krusell, "Macroeconomic Implications of InvestmentSpecific Technological Change," mimeo, 1994.

Greenwood, J. and B. Jovanovic, "Financial Development, Growth and the Distribution of Income," Loumal of Political Economy, 98 (1990), 1076-1107.

Hall, R. "The Role of Consumption in Economic Fluctuations," in The American Business Cycle: Continuity and Change, ed. by Robert Gordon, Chicago: University of Chicago Press, 1986, 237-55.

Hamilton, J. "Monetary Factors in the Great Depression," Joumal of Monetary Economics, 19 (1987), 145-69.

, "A New Approach to the Economic Analysis of Nonstationary Time Series and the Business Cycle," Econometrica, 57 (1989), 357-84. 
Jovanovic, B. "Observable Implications of Models with Multiple Equilibria," Econometrica, 57 (1989), 1431-38.

Kendrick, J.Productivity Trends in the United States, Princeton: Princeton University Press, 1961.

Kendrick, J.Post-War Productivity Trends in the United States. 1948-69, New York: Columbia University Press, 1973

King, R., Plosser, C. and S. Rebelo, "Production, Growth and Business Cycles: I. The Basic Neoclassical Model," Joumal of Monetary Economics, 21 (1988), 195-232.

Kuznets. S. National Income and Its Composition, 1919-38, National Bureau for Economic Research: New York, 1941.

Marimon, R. and A. Marcet, "Communication, Commitment and Growth, "Lournal of Economic Theory, 58 (1992), 219-49.

Mishkin, F. "The Household Balance Sheet and the Great Depression, " Journal of Economic History, 38(1978), 918-37.

Romer, C. "World War I and the post war depression: A reinterpretation based on alternative estimates of GNP," Joumal of Monetary Economics, 22 (1988), 91-116.

Romer, C. "The Great Crash and the Onset of the Great Depression," Quarterly Joumal of Economics, 105 (1990), 597-624.

Romer, C. "The Nation in Depression," Joumal of Economic Perspectives, 7 (1993), 19-40.

Smith, B. "Bank Panics, Suspensions and Geography: Some Notes on the Contagion of Fear in Banking," Economic Inquiry, 29 (1991), 230-48.

Stokey, N. and R. Lucas, Recursive Methods in Economic Dynamics, Harvard University Press: Cambridge, Mass., 1989.

Temin, P. Did Monetary Forces Cause the Great Depression? New York: W.W. Norton, 1976.

Weil, P. "Increasing Returns and Animal Spirits," American Economic Review, 79 (1989), 889-94.

Williamson, S. "Bank Failures, Financial Restrictions and Aggregate Fluctuations: Canada and the United States, 1870-1913," Federal Reserve Bank of Minneapolis, Quarterly Review, Spring 1989, 20-40. 
Appendix: Proofs

As discussed in the text, $k=\left[k_{p}^{*}, k_{0}\right]$ and where $k_{j}^{*}$ satisfies $k_{j}^{*}=k^{\prime}\left(k_{j}^{*}, \theta_{j}\right)$ for $j=0, p$. From our simulations, this restriction on the state space is not binding since the economy fluctuates between these two capital stock levels.

Proposition 1: There exists a $V(k, \theta)$ that satisfies (1) for $k \in k$.

Proof: The proof uses Proposition 9.6 from Stokey-Lucas [1989]. To make use of their result, we note that the return function is bounded and continuous for $k \in x$, the feasible set is non-empty, compact valued and continuous and that our problem has discounting.

Proposition 2: There exists a value of $F$ such that an equilibrium exists with $\mathrm{V}\left(\mathrm{k}, \theta_{\mathrm{o}}\right) \neq \mathrm{V}\left(\mathrm{k}, \theta_{\mathrm{p}}\right)$ for all $\mathrm{k} \in \mathrm{k}$.

Proof: Let $I\left(k, \theta_{0}\right)$ be the investment choice that is optimal for the agent in state $\left(k, \theta_{0}\right)$. Since the capital stock is always less than $k_{b}^{\circ}$, this investment flow will be strictly positive and is positive even at $\left(\mathrm{k}_{\mathrm{o}}^{*}, \theta_{\mathrm{o}}\right)$ since there is depreciation of the stock. Let $\mathrm{I}_{\min }\left(\mathrm{k}, \theta_{\mathrm{a}}\right)$ be the smallest level of investment observed under optimism. Set the critical level of the fixed cost, $\mathrm{F}^{*}$, such that the returns to investing $\mathrm{I}_{\min }\left(\mathrm{k}, \theta_{2}\right)$ using the intermediated technology is the same as the return from the mattress. For $I>I_{\min }\left(k, \theta_{\alpha}\right)$, the intermediated technology will dominate due to the presence of the fixed cost. Thus, if others are investing using the intermediaries, the representative agent will do so as well. In the case of the pessimistic outcome, we assume that the costs of starting up the intermediation process for a single agent are prohibitive and thus a mattress equilibrium always exists. 
Table 1

Intermediated Investment

\begin{tabular}{|c|c|c|c|c|c|c|c|c|c|c|}
\hline & & \multicolumn{5}{|c|}{$\begin{array}{l}\text { Corr. with } Y \\
\text { Contemporaneous }\end{array}$} & \multicolumn{4}{|c|}{$\begin{array}{c}\text { Standard Deviation Relative to } \\
\text { Output }\end{array}$} \\
\hline & C & $\mathbf{H}$ & I & Prod & $\mathbf{R}$ & t & C & H & I & Prod \\
\hline Pooled & .55 & .50 & .65 & .70 & -.98 & -.95 & .95 & .74 & 5.3 & .90 \\
\hline Optimism & .99 & -.98 & -.98 & .99 & -.99 & -.99 & 2.6 & 1.2 & 6.4 & 2.2 \\
\hline Pessimism & .99 & -.99 & -99 & .99 & -.99 & -.99 & 2.7 & 1.5 & 8.5 & 2.5 \\
\hline
\end{tabular}

Table 2

U.S. Data

\begin{tabular}{|c|r|r|r|r|r|r|r|r|r|r|}
\hline \multicolumn{1}{|c|}{} & \multicolumn{4}{c|}{ Contemporaneous Correlation with } \\
Output
\end{tabular}

${ }^{1} \mathrm{King}$, Plower and Rebelo [1988] in loge and linear detrending for all variables except $\mathrm{K}$, which comes from Citibane and is annual, and $C D$, which is quarterly expenditures on durables from Citibase.

2 Computed uning anoual data from Kendrick [1961], in loga, per capila and linandy detrendod. 
Table 3

Intermediated Investment and Durable Consumption ${ }^{1}$

\begin{tabular}{|c|c|c|c|c|c|c|c|c|c|c|}
\hline & \multicolumn{5}{|c|}{ Contemporaneous Correlation with $\mathbf{Y}$} & \multicolumn{5}{|c|}{ Standard Deviation Relative to Output } \\
\hline & CN & CD & H & I & Prod & CN & $C D$ & H & I & Prod \\
\hline Pooled & .37 & .65 & .73 & .83 & .64 & .74 & 7.76 & .77 & 4.0 & .68 \\
\hline Opt. & .80 & .12 & -.34 & -.06 & .86 & 1.7 & 10.4 & .82 & 3.1 & 1.5 \\
\hline Pess. & .67 & .07 & -.39 & -.26 & .72 & 2.7 & 25.7 & 1.71 & 7.3 & 2.3 \\
\hline
\end{tabular}

' CN is consumption of non-durables, CD is expendibure on durables and ifis physical capita inverment. 
Appendix: Proofs

As discussed in the text, $k=\left[k_{p}^{*}, k_{0}\right]$ and where $k_{j}^{*}$ satisfies $k_{j}^{*}=k^{\prime}\left(k_{j}^{*}, \theta_{j}\right)$ for $j=0, p$. From our simulations, this restriction on the state space is not binding since the economy fluctuates between these two capital stock levels.

Proposition 1: There exists a $V(k, \theta)$ that satisfies (1) for $k \in k$.

Proof: The proof uses Proposition 9.6 from Stokey-Lucas [1989]. To make use of their result, we note that the return function is bounded and continuous for $k \in \kappa$, the feasible set is non-empty, compact valued and continuous and that our problem has discounting.

Proposition 2: There exists a value of $F$ such that an equilibrium exists with $\mathrm{V}\left(\mathrm{k}, \theta_{\mathrm{o}}\right) \neq \mathrm{V}\left(\mathrm{k}, \theta_{\mathrm{p}}\right)$ for all $\mathrm{k} \in \mathrm{x}$.

Proof: Let $\mathrm{I}\left(\mathrm{k}, \theta_{\mathrm{o}}\right)$ be the investment choice that is optimal for the agent in state $\left(k, \theta_{0}\right)$. Since the capital stock is always less than $k_{0}^{*}$, this investment flow will be strictly positive and is positive even at $\left(k_{0}^{*}, \theta_{0}\right)$ since there is depreciation of the stock. Let $I_{\min }\left(k, \theta_{0}\right)$ be the smallest level of investment observed under optimism. Set the critical level of the fixed cost, $F^{*}$, such that the returns to investing $I_{\min }\left(k, \theta_{0}\right)$ using the intermediated technology is the same as the return from the mattress. For $I>I_{\min }\left(k, \theta_{0}\right)$, the intermediated technology will dominate due to the presence of the fixed cost. Thus, if others are investing using the intermediaries, the representative agent will do so as well. In the case of the pessimistic outcome, we assume that the costs of starting up the intermediation process for a single agent are prohibitive and thus a mattress equilibrium always exists. 


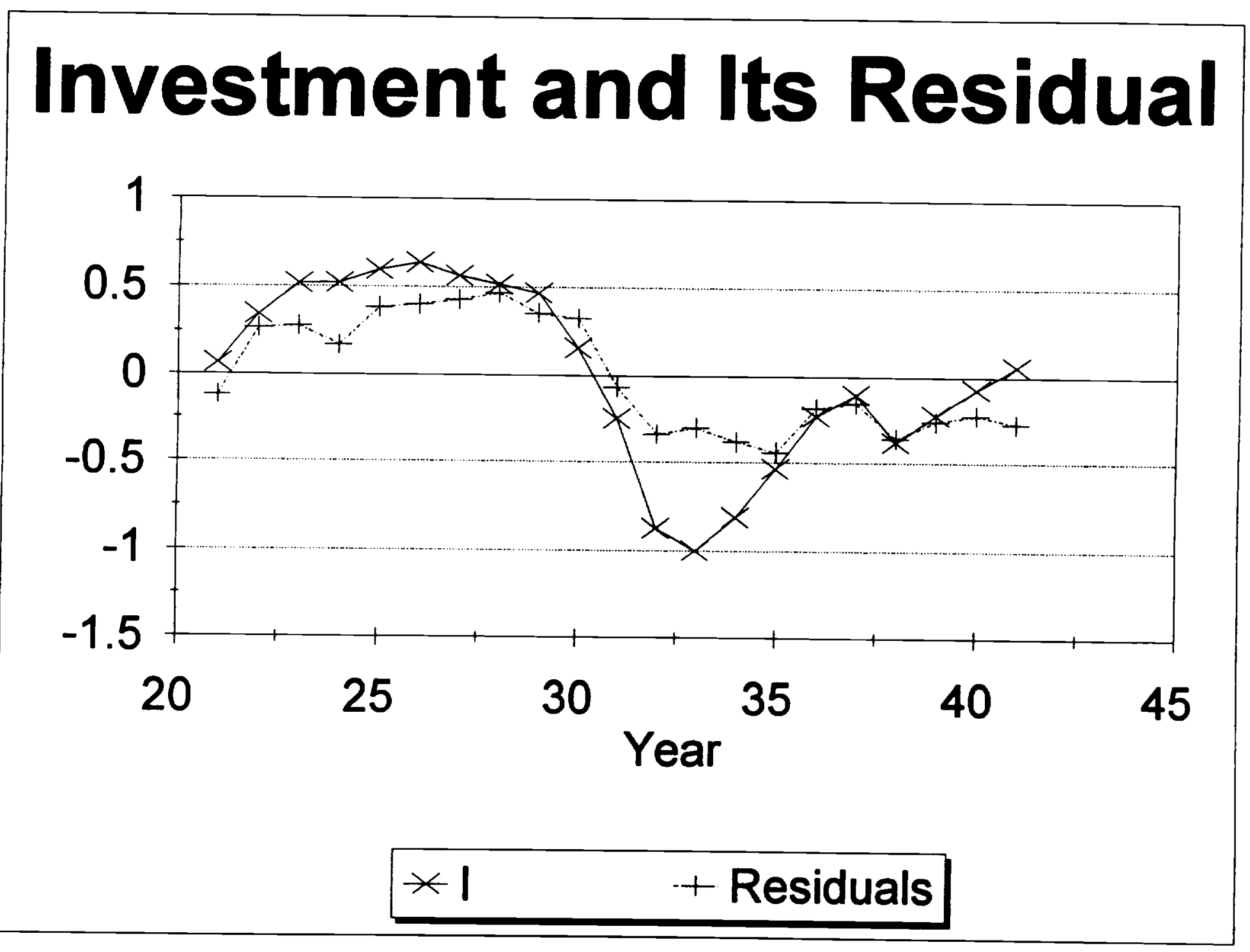

Figure 1 


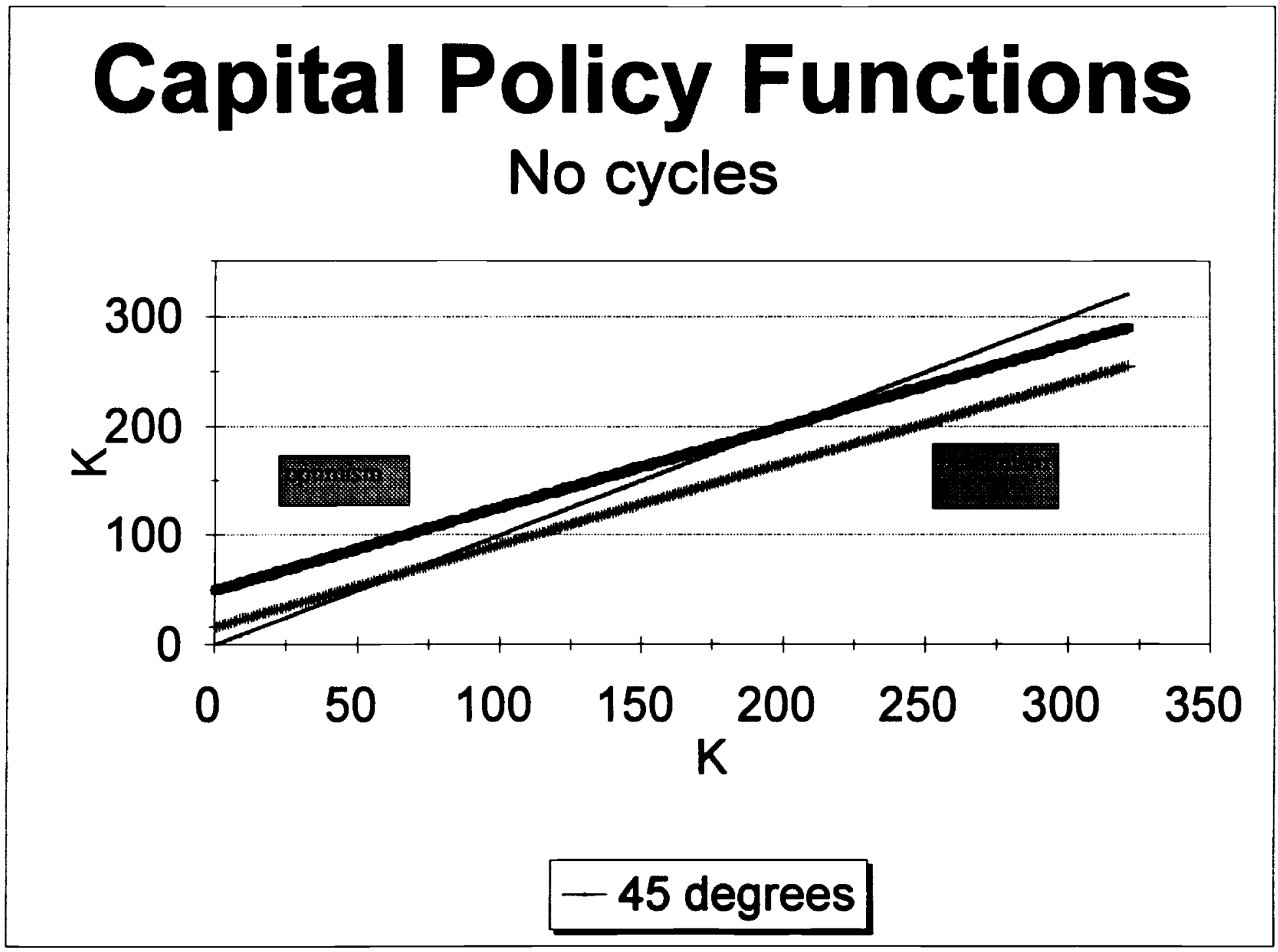




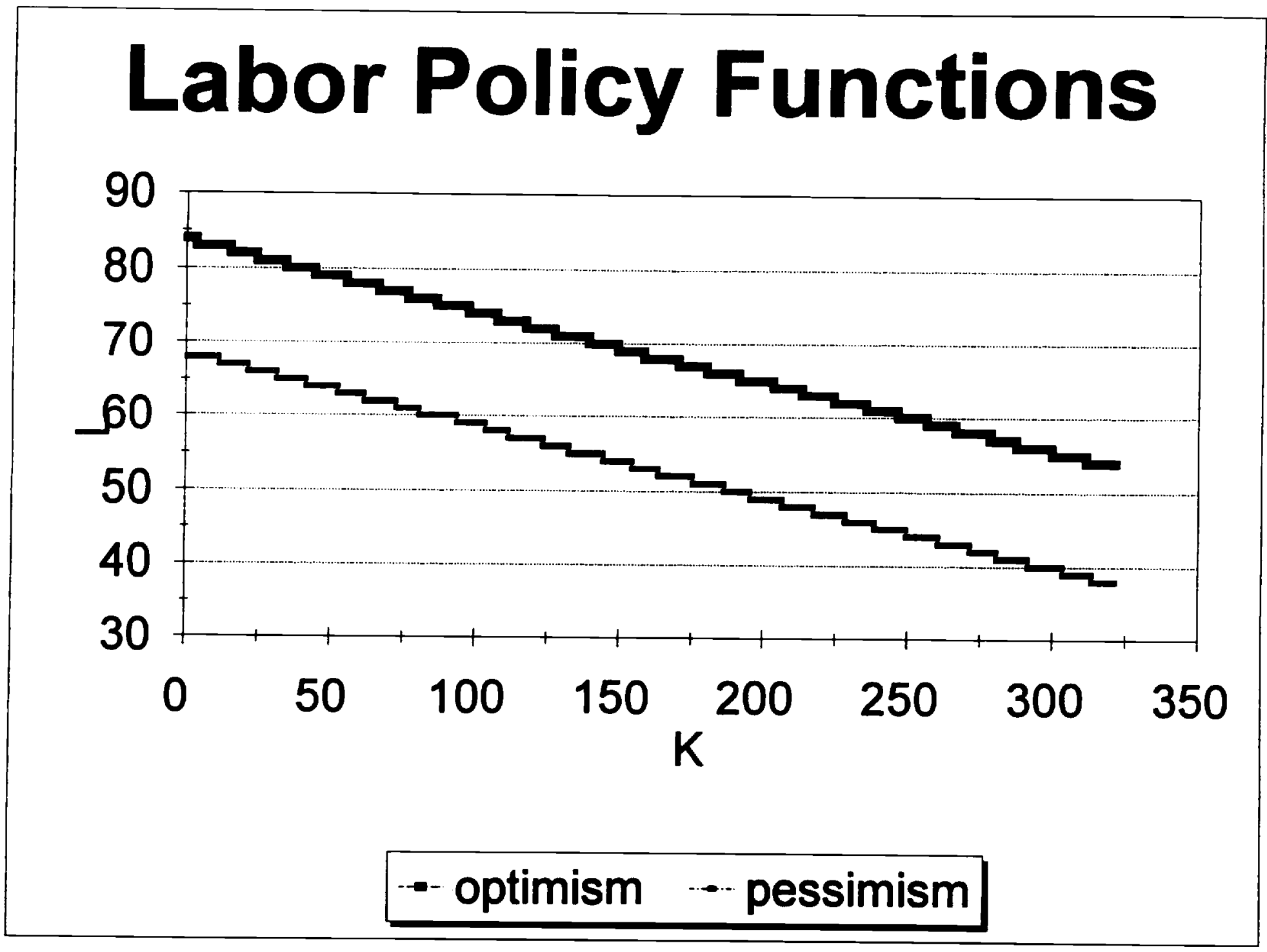

Figure $2 b$ 


\section{Real Variables Simulation: No Cycles}

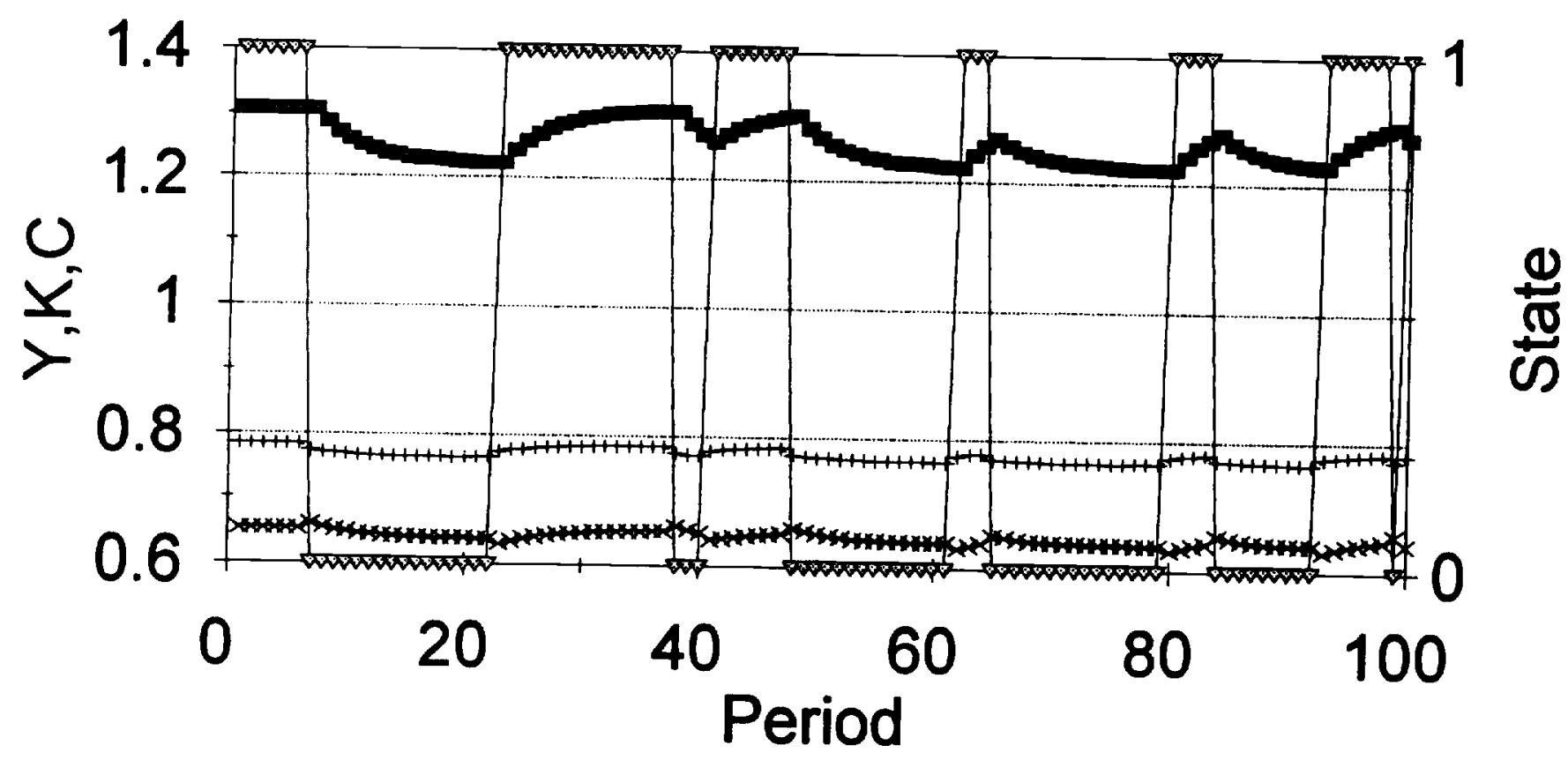

$$
\rightarrow \mathrm{Y} \quad-\mathrm{K} \quad * \mathrm{C} \quad \rightarrow \text { State }
$$




\section{Real Variables Simulation: No Cycles}

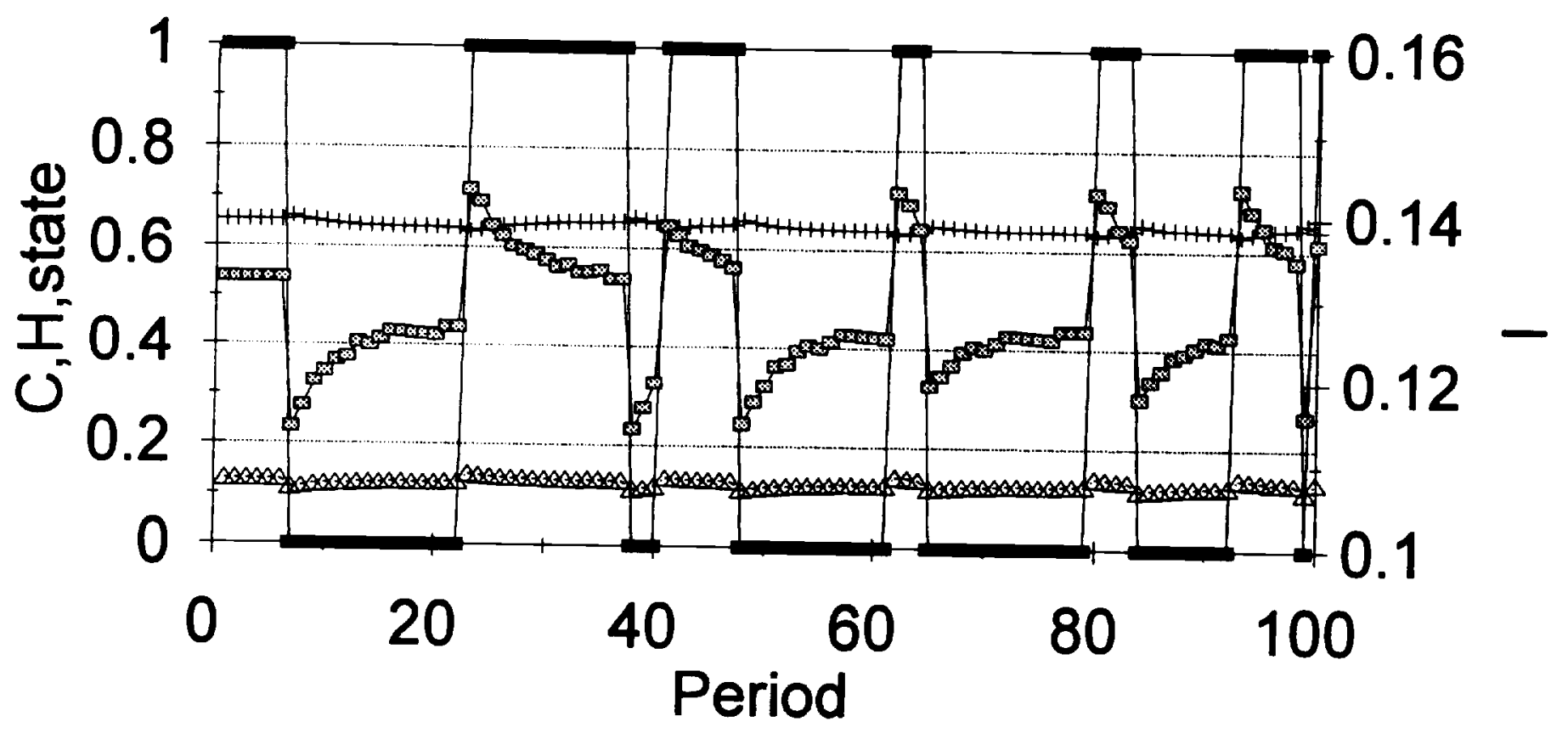

$$
\rightarrow \mathrm{C} \quad \Delta \mathrm{H} \quad-\text { State } \rightarrow-\mathrm{I}
$$




\section{Financial Variables Simulation: No Cycles}

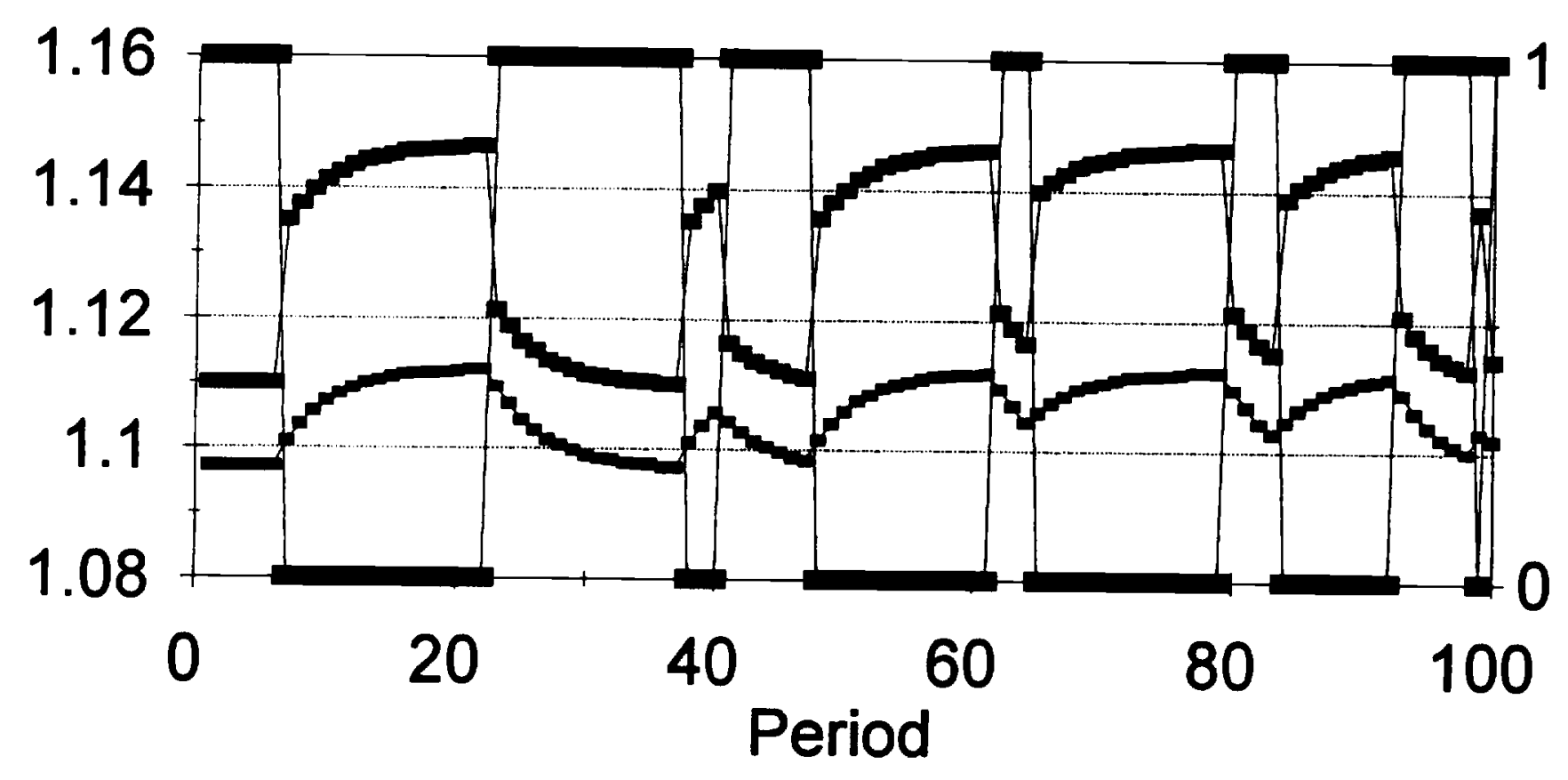

$$
-\mathrm{R} \quad-\text { rd }- \text { state }
$$




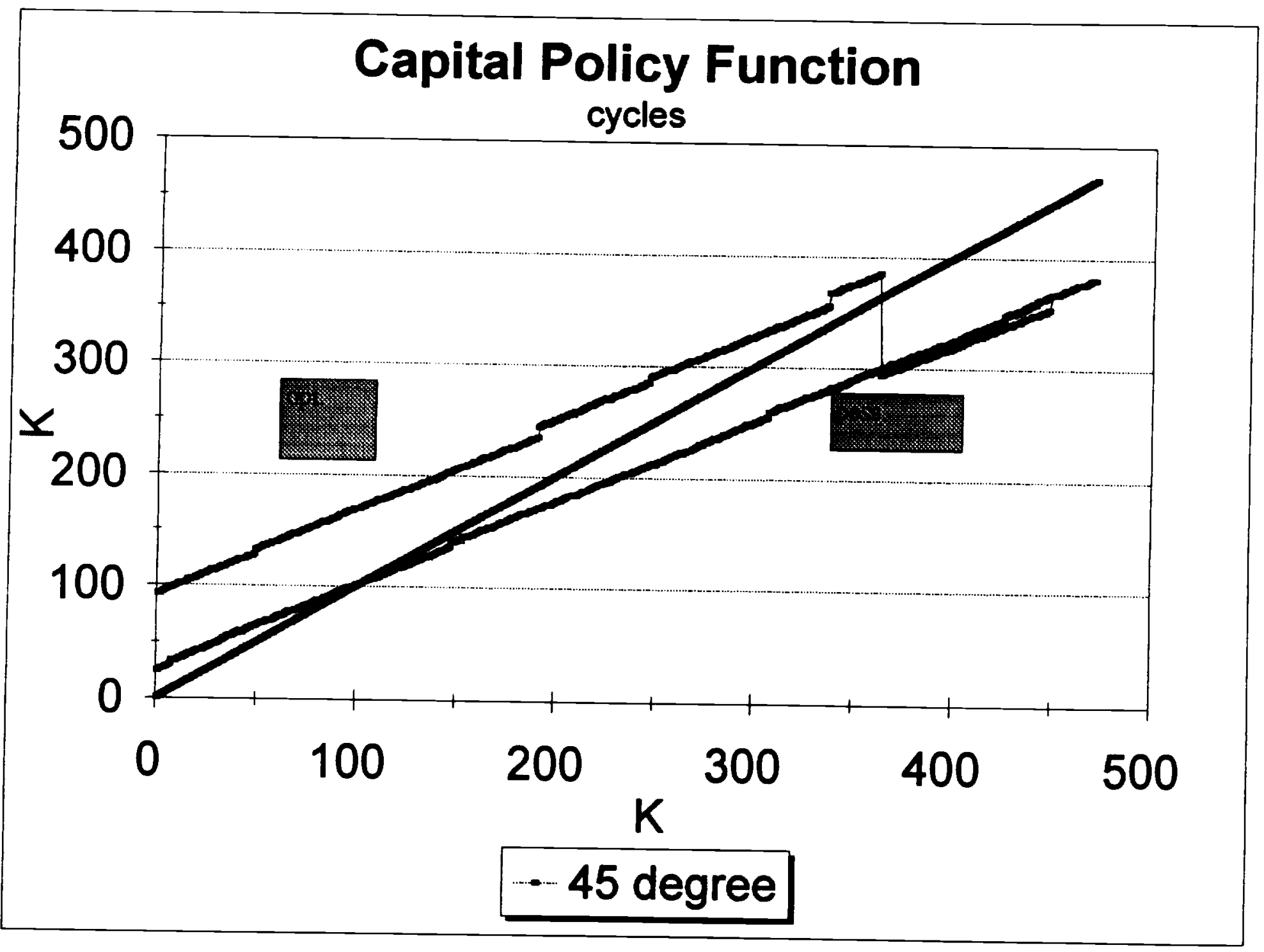

Figure 6 


\section{Con., Inv. and Output (Kendrick) 1921-41}

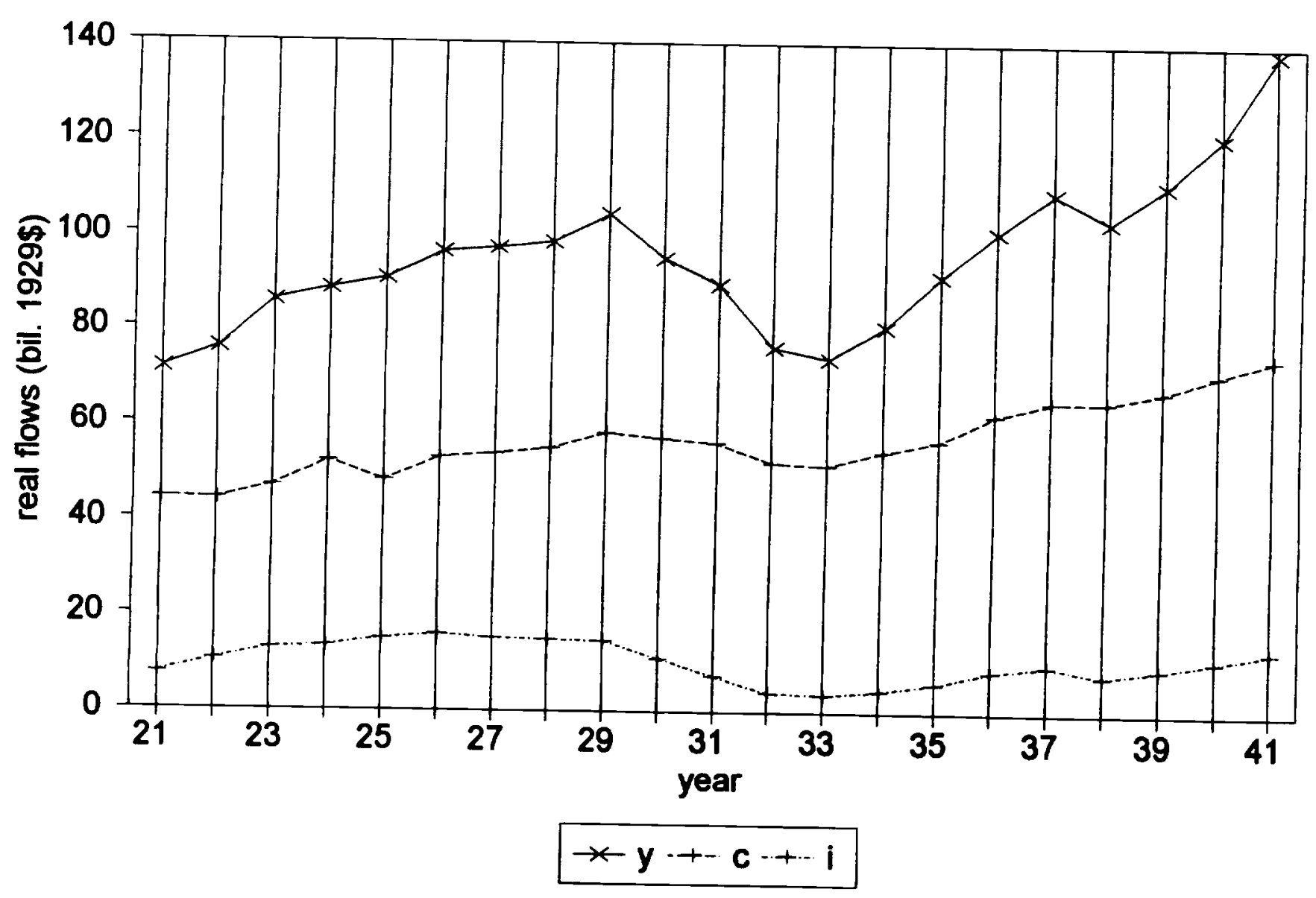




\section{Productivity Movements Kendrick}

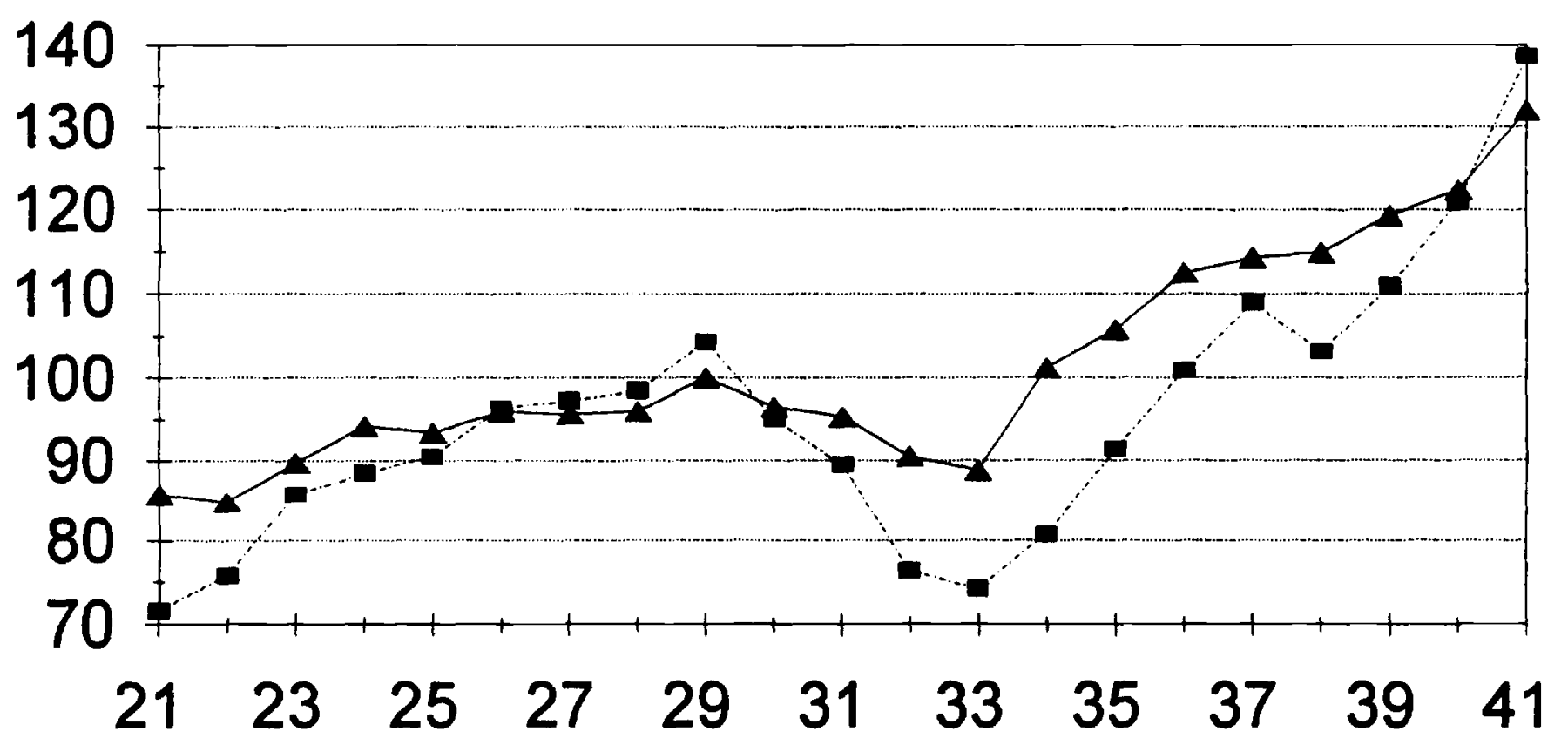




\section{Con. Dur. Exp. to Consumption}

1922-41

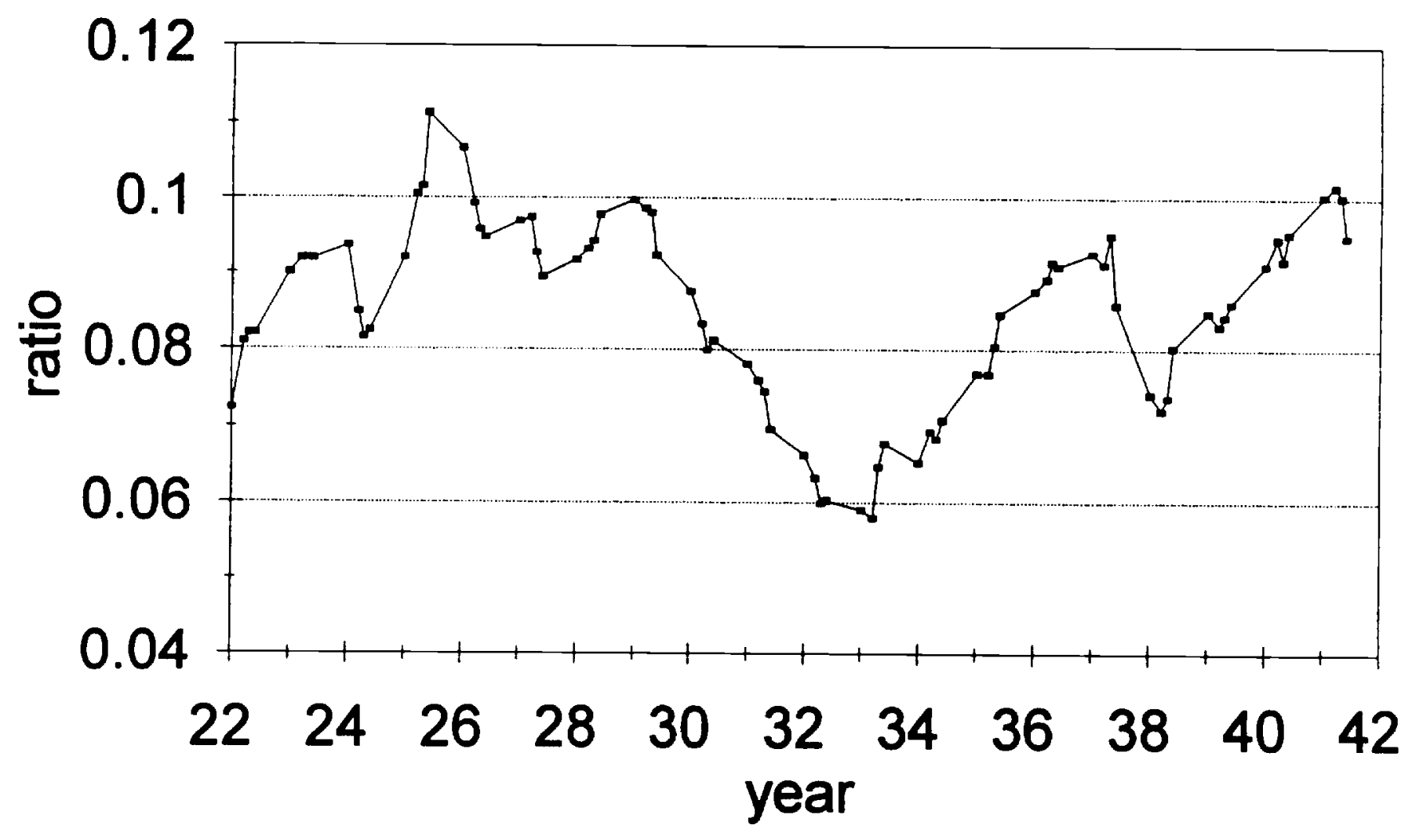

